\title{
Berufsorientierung jugendlicher Geflüchteter
}

\subsection{Bedeutung des Themas Berufsorientierung}

\section{Bis auf wenige Ausnahmen halten die meisten der Befragten die Berufs- orientierung für ein zentrales Thema in ihrer jetzigen Lebensphase.}

Einige wenige Befragte haben nach eigener Meinung noch nicht den Zeitpunkt erreicht, um sich bereits ernsthaft mit dem Thema Berufswahl zu befassen, oder konzentrieren sich zunächst auf den Spracherwerb und die Schule.

„Ich möchte zunächst die deutsche Sprache lernen. Darauf ist momentan mein Fokus gerichtet." (männlich, 17, Afghanistan)

„Momentan hat die Schule die allerhöchste Priorität.“ (männlich, 16, Afghanistan)

„Ich bin schulisch noch nicht so weit. Ich würde mich dann in einem Jahr informieren und eventuell auch ein Praktikum machen." (männlich, 17, Irak)

„Ich denke momentan nicht viel an Arbeit. Später werde ich noch oft genug an Arbeit denken müssen." (männlich, 17, Irak)

„Wichtig ist für mich im Moment die Schule und der Integrationskurs. Ausbildung und Arbeit kommen dann erst. Ohne den Integrationskurs kannst du hier in Deutschland nichts machen. Die berufliche Zukunft ist wichtig, aber sie beschäftigt mich im Moment nicht." (männlich, 17, Eritrea)

Einige betonen, dass sie sich aufgrund der Flucht und der damit verbundenen problematischen Lebenssituation überfordert fühlen, sich auch noch mit dem Thema Berufsorientierung auseinanderzusetzen. 
„Ich musste alles neu machen. Ich musste die Sprache neu lernen, eine neue Schule besuchen und neue Leute kennenlernen." (männlich, 16, Syrien)

„Es gab Momente, in denen ich Selbstmordgedanken hatte. Aber bei uns ist es eine Sünde, sich selbst umzubringen. Ich war dann bei einem Psychologen. Er hat mir sehr geholfen. Er ist ein Arzt aus Libyen und hat mir wirklich geholfen. [...] Ich habe mal daran gedacht, Gerïstbauer zu werden. Aber eine Betreuerin hat es nicht zugelassen. Sie hat gesagt: ,Der Junge ist krank im Kopf, er kann nicht 50 Meter hochgehen.' Genauso hat sie es gesagt.“ (männlich, 17, Irak)

„Wie sollst du dich mit diesem Thema beschäftigen, wenn du noch keine Bleibeperspektive hast, die schulische Voraussetzung noch nicht erfüllst? “ (männlich, 17, Eritrea)

Die große Mehrheit der Jugendlichen, die im Rahmen der Studie befragt wurden, schreibt dem Thema Berufswahl eine sehr hohe Bedeutung zu. Für viele zählt die Berufsausbildung, gefolgt von Familie und Religion, zu den zentralen Themen im Leben.

„Ich denke, das steht an erster Stelle. Denn die meiste Zeit des Lebens verbringt man später mit arbeiten." (männlich, 16, Syrien)

„Ich denke, Arbeit ist eine der wichtigsten Dinge im Leben eines Menschen.“ (weiblich, 17, Syrien)

„Ich will nicht warten, bis das Sozialamt oder das Jobcenter mir Geld überweisen. Ich will auf meinen eigenen Füßen stehen. Daher habe ich auch das Gymnasium verlassen, um arbeiten zu gehen." (männlich, 17, Afghanistan)

„Eine Ausbildung ist eines der wichtigsten Dinge in meinem Leben. Wenn ich das geschafft habe, dann habe ich meinen Traum verwirklicht." (weiblich, 17, Syrien)

„An erster Stelle steht die Familie, dann der Beruf. Wenn ich dann genug habe, dann baue ich mir ein Haus und gründe eine Familie.“ (männlich, 17, Syrien)

„Berufsorientierung steht für mich an zweiter Stelle nach der Religion.“ (männlich, 17, Syrien)

\section{Die jungen Geflüchteten sehen Deutschland als Land der Chancen, wo sie sich selbst verwirklichen können.}

Neben der Sicherheit, die sie hier haben, schätzen die jungen Geflüchteten Deutschland als einen Staat, der den Menschen die strukturellen bzw. rechtlichen Voraussetzungen für soziale Absicherung und Aufstiegschancen bietet. In ihren Herkunftsländern sehen die meisten hingegen keine Möglichkeit, sich in absehbarer Zeit eine selbstbestimmte Zukunft aufzubauen (Brücker et al. 2016c, 32). 
Alle Befragten sind sich dabei einig, dass Bildung der zentrale Schlüssel zu einem guten Leben in Deutschland ist.

„Hier in Deutschland hat man eine Zukunft, in Syrien nicht. Hier wird man zum Schulbesuch motiviert." (männlich, 16, Syrien)

„In Syrien ist die Zukunft, auch wenn man sich um seine Bildung kümmert, nicht einfach gestaltbar, hier hat man mehr Möglichkeiten." (weiblich, 15, Syrien)

„Ich will jetzt lernen. Das wollte ich zwar auch schon in Afghanistan, aber da hatte ich keine Zukunft. Früher wollte ich lernen und studieren, und hier kann ich das auch!" (weiblich, 15, Afghanistan)

\section{Die Jugendlichen beschäftigt es sehr, dass ihre Zukunftspläne von der Asylpolitik abhängen, vor allem die afghanischen Jugendlichen.}

Nicht zu wissen, ob sie in Deutschland bleiben dürfen oder ob eine Familienzusammenführung möglich ist, setzt einige der Jugendlichen enorm unter Druck und macht ihnen Angst. Die syrischen Jugendlichen, die in der Regel davon ausgehen, dass sie in Deutschland bleiben können, erwähnen in den Interviews häufig ein Gefühl der Ohnmacht in Bezug auf die Frage der Familienzusammenführung.

„Ich würde gerne meine Opas herholen. Ich fühle mich in der Situation machtlos. Immer wenn jemand über Syrien spricht, muss ich an meine Opas denken. Also eigentlich jeden Tag. “ (weiblich, 14, Syrien)

„Ich fühle mich im Alltag eigentlich nicht machtlos. Nur bezüglich meines Aufenthalts, der mir für ein Jahr bewilligt wurde. Damit kann ich meine Familie leider nicht nach Deutschland holen. Und deswegen muss ich mich bemühen, einen Anwalt einzuschalten." (männlich, 16, Syrien)

Die befragten Jugendlichen aus Afghanistan, dem Irak und Eritrea sind hingegen deutlich pessimistischer, was ihre Bleibeaussichten anbelangt. Die Angst vor Abschiebung bremst die Jugendlichen bei ihren Bildungsbemühungen bzw. der Berufsorientierung aus.

„Ich bin noch unsicher, was ich werden möchte, und habe Sorgen, dass ich plötzlich abgeschoben werde." (männlich, 16, Irak)

„Ich habe ja gesagt, ich will so gerne Lehrerin werden und weiter zur Schule gehen, aber das Problem ist, dass wir abgelehnt wurden. Manchmal verliere ich die Hoffnung! Ich habe so viele Wünsche, aber Ablehnung heißt, dass wir vielleicht zurückgeschickt werden. Das ist alles ungewiss. Unser Schicksal ist irgendwie ungewiss. 
Ich lerne so viel, aber manchmal frage ich mich, wieso ich das alles mache. Es wäre mir wichtig, dass wir irgendeine Sicherheit hätten, dass ich mit ruhigem Kopf lernen könnte." (weiblich, 15, Afghanistan)

„Wenn du noch keinen Aufenthaltsstatus hast und dein Antrag noch nicht abschließend entschieden wurde, bereitet dir das Kummer. Der Kummer ist irgendwie immer da in deinem Alltag. Wenn du etwas Beunruhigendes hörst oder miterlebst, wie zum Beispiel, dass Leute abgeschoben wurden, verstärkt sich der Kummer. Manchmal wird es unerträglich. Es wird zu schwer für dich.“ (männlich, 17, Eritrea)

„Ich sehe meine Zukunft eher in Deutschland. Aber wenn ich hier nicht anerkannt werde, muss ich leider zurück. Ich will auch nicht zurück.“ (männlich, 16, Afghanistan)

„Ich fühle mich gut, aber mein älterer Bruder hat eine Ablehnung bekommen und muss wieder zurück nach Afghanistan. Daher bin ich etwas nervös. [...] Mein Bruder hat nach seiner Ablehnung die Schule nicht mehr besucht. Vielleicht kommt das auch auf mich zu." (männlich, 17, Afghanistan)

Einige der älteren männlichen afghanischen Jugendlichen kritisieren explizit die deutsche Migrationspolitik als rassistisch, zynisch und unentschlossen.

„Ich denke oft über das Thema Berufsausbildung nach, da nur 20 Prozent der Afghanen hier einem Beruf nachgehen. Also die können weder ihren Familien helfen, noch zahlen sie Steuern an den Staat." (männlich, 17, Afghanistan).

„Die westlichen Länder haben Krieg in unseren Ländern angezettelt, damit wir hier Niedriglohnjobs ausüben und sie hier billige Arbeitskräfte haben. Einer hat mich mal gefragt, warum Deutschland nicht aus Portugal oder aus Griechenland Billiglohnarbeiter in das Land holt. Daraufhin habe ich geantwortet, dass das auch Europäer sind und sie lieber Leute aus dem Orient dafür haben wollen. “ (männlich, 17, Afghanistan)

„Was mir nicht gefällt, ist diese Debatte mit den sicheren Herkunftsländern. Wenn es in Afghanistan Bomben regnet, dann ist es kein sicheres Herkunftsland. Wenn jedoch zwei bis drei Wochen keine Bomben fallen, dann ist es plötzlich ein sicheres Herkunftsland. Mir gefällt diese Willkür nicht. Sicher gibt es hier ein paar Flüchtlinge, die Schlechtes tun und wieder zurückkommen. Aber viele gehen hier zur Schule und sollten nicht zurück in ein Kriegsland. Deutschland sollte sich endlich entscheiden, ob es alle behalten oder zurückschicken will.“ (männlich, 17, Afghanistan) 


\section{Die meisten Befragten sind optimistisch, was ihre schulischen bzw. beruflichen Chancen in Deutschland betrifft. Jugendliche, die von Abschiebung bedroht sind, haben teilweise die Hoffnung auf eine berufliche Zukunft in Deutschland verloren.}

Insgesamt blickt die Mehrheit der befragten jungen Geflüchteten positiv in die eigene schulische und berufliche Zukunft in Deutschland - besonders im Vergleich zu den Möglichkeiten im Herkunftsland.

„Hier gibt es viel mehr Möglichkeiten. Und ein Zeugnis aus Deutschland ist anerkannter als eines aus Syrien." (männlich, 16, Syrien)

„Die Zukunft ist gut. Ich habe hier die Chance auf eine Zukunft.“ (männlich, 17, Irak)

„In Afghanistan kann man sich nicht wirklich weiterbilden und etwas lernen, weil man ein unruhiges Leben führt. [...] Ich bin hierhergekommen, also sehe ich meine Zukunft hier. Ich möchte mir hier eine Zukunft aufbauen, und hier ist auch meine Zukunft." (männlich, 17, Afghanistan)

Die Jugendlichen, die bereits zur Ausreise aufgefordert wurden oder die mit einem Ablehnungsbescheid rechnen, sind deutlich pessimistischer. Einige äußern sich stark verunsichert und hilflos. Sie versuchen aber, die Hoffnung nicht aufzugeben, zumindest die Ausbildung in Deutschland abschließen zu dürfen.

„Wir haben zweimal das Interview gemacht für den Aufenthalt, aber leider nicht bestanden, und das macht mich unzufrieden. [...] Ich hätte gerne einen Aufenthaltstitel, sodass ich die Gewissheit habe, dass ich hierbleiben darf." (männlich, 15, Irak)

„Ich werde wahrscheinlich in Deutschland bleiben, aber ich zweifle im Moment daran. Wir wurden abgelehnt, aber ich kann mir nicht vorstellen, in Afghanistan zu sein. Das wäre so schwer, wieder zurückzugehen. Wir waren so lange hier, wir haben so viel gelernt. Manchmal, wenn ich viel lerne, frage ich mich, wofür ich das mache, wenn sie uns am Ende zurückschicken." (weiblich, 15, Afghanistan)

„Ich fühle mich gut und frei. Aber seitdem wir unseren Ablehnungsbescheid bekommen haben, leben wir etwas unter Stress. [...] Aber man sagt, dass man definitiv eine höhere Chance auf ein Bleiberecht hat, wenn man arbeitet. Ich weiß nicht, ob ich dann anerkannt werde oder nicht. Wenn wir hier eine Aufenthaltsgenehmigung bekommen, sehe ich mich definitiv in Deutschland, da es mein Lieblingsland in Europa ist." (männlich, 17, Afghanistan) 


\section{Die meisten Befragten sind bereit, ihre Zukunftspläne flexibel und pragmatisch anzugehen.}

In den meisten Fällen hängt diese optimistische Haltung der Jugendlichen mit einem ausgeprägten Pragmatismus zusammen. Sie gehen davon aus, auch glücklich werden zu können, wenn sich der Traumberuf nicht (sofort) erreichen lässt, sie nicht (sofort) das Lieblingsfach an der präferierten Hochschule studieren können oder sie nicht (sofort) die große Karriere vor Augen haben. Dieser Pragmatismus und die Kompromissbereitschaft können verschiedene Gründe haben:

- Die Jugendlichen sehen eine große Bandbreite an Möglichkeiten in Deutschland, falls es mit dem ersten Berufswunsch nicht klappt.

„Ich fühle mich wohl. [...] Ich denke, dass der Beruf des Bankkaufmanns sehr sicher ist. Und wenn doch mal irgendetwas sein sollte, dann mache ich halt eine andere Ausbildung in der Körperpflege." (männlich, 16, Syrien)

- Sie führen sich die besseren beruflichen Möglichkeiten in Deutschland gegenüber denen in den Herkunftsländern vor Augen.

„Ich habe das Gefühl, dass mir hier viele Türen offenstehen. Selbst wenn ich keine Polizistin werde, ich kann hier so viel anderes machen." (weiblich, 14, Syrien)

- Sie vertrauen auf den eigenen Willen, alles dafür zu tun, die Chancen, die sich in Deutschland ergeben, auch zu nutzen.

„Leider werde ich hier nicht studieren können. Da ich fünf Sprachen kann, ist Hotelkaufmann der passende Beruf. Außerdem bringe ich auch andere benötigte Eigenschaften mit, wie z. B. Freundlichkeit. [...] Ich werde nach der Ausbildung natürlich nicht direkt als Manager arbeiten, aber ich werde mich sicher hocharbeiten. Nach der Ausbildung beginne ich als Hotelangestellter und bringe es durch gute Leistungen vielleicht irgendwann zum Hoteldirektor oder vielleicht sogar zum Hoteleigentümer." (männlich, 16, Syrien).

\section{Differenzierung nach Mindset}

Die obigen Ergebnisse gelten für jugendliche Geflüchtete generell. Bei der Filterung der Fälle nach Mindsets zeigen sich allerdings interessante Akzentunterschiede. 
- Die Jugendlichen im Mindset Moving Up sind besonders stark auf ihre Zukunft fokussiert. Fast alle identifizierten das Thema Berufsorientierung als wichtig, und für die meisten hat es derzeit höchste Priorität.

- Von allen Befragten nannten diese Jugendlichen am häufigsten Karriere und Erfolg als zentrale Werte. Typisch für diese Gruppe ist auch eine kompetitive, rivalisierende Grundhaltung.

„Es ist das Wichtigste für mich, dass etwas aus mir wird. Also ist das Thema Beruf sehr wichtig." (weiblich, 15, Syrien)

„Ich will einfach meinen Traum verwirklichen, für den ich nach Deutschland gekommen bin. [...] Wenn ich das nicht schaffe, dann werde ich mich sehr schämen." (weiblich, 14, Syrien)

„Noten, die schlechter sind als eine 3, werden von mir verbrannt oder weggeschmissen. [...] In meiner Klasse sind viele Afghanen und ein paar Afrikaner, und ich freue mich, wenn ich bei den Klausuren besser als die abschneide." (männlich, 17, Afghanistan)

Die Jugendlichen in der Mindset-Gruppe „Moving up“ schätzen insbesondere Transparenz und Korruptionsfreiheit bei den Ausbildungs- und Berufsmöglichkeiten in Deutschland. Rechtsstaatlichkeit und Chancengleichheit sind ihrer Meinung nach die Voraussetzungen für die guten Bedingungen in Deutschland, was im Vergleich mit den Verhältnissen im Herkunftsland deutlich wird:

„In Afghanistan kann man alles erreichen, solange man genügend Geld hat. Das ist in Deutschland nicht der Fall. Hier spielt das Geld nicht so eine große Rolle für die Berufsausbildung. Und es gibt hier wenig Korruption." (männlich, 17, Afghanistan)

„In Afghanistan hätte ich für einen guten Beruf eine Menge Schmiergeld zahlen müssen. Hier kann ich das problemlos lernen." (männlich, 17, Afghanistan)

„, Man kann hier in Deutschland nicht ohne eine Ausbildung arbeiten. Im Irak kann jeder alles machen, auch ohne eine Ausbildung, Hauptsache, das Geld stimmt dort. Die Gesetzgebung ist hier sehr gut." (weiblich, 17, Irak)

- Auch für die Befragten im Mindset Breaking Free sind Ausbildung und Beruf wichtig. Etwa die Hälfte bezeichnet das Thema Berufsorientierung als ihre höchste Priorität, die andere Hälfte nennt es ,wichtig“. Einige dieser Jugendlichen scheinen am Bildungsprozess selbst genauso interessiert zu sein wie an den Ergebnissen. In dieser Gruppe wird am häufigsten eine gute Ausbildung als Grundwert genannt, am seltensten Karriere oder Erfolg. 
„Zum einen bin ich ein Mensch, der viele Fragen hat und der viel wissen will. Das ist sogar manchmal ein Problem. Ich frage so viel, und mein Vater muss dann manchmal sagen, dass er auch nicht alles weiß. Deswegen mag ich es, über die Vergangenheit zu lesen. Gerne lese ich auch über Theorien oder Philosophen wie Sokrates. Ich interessiere mich sehr dafür." (weiblich, 14, Syrien)

„Ich möchte immer etwas Neues lernen. Ich will später ein Mensch sein, der viel gelernt hat und über viele Themen Bescheid weiß.“ (weiblich, 15, Irak)

- Die Jugendlichen im Mindset Holding On halten das Thema Berufsorientierung zwar für wichtig, nennen aber seltener Bildung, Karriere oder Erfolg als Grundwerte. Für sie haben Familie und Freundschaft Vorrang. Auffällig in dieser Gruppe ist, dass viele sich ambivalent oder unklar über ihre Zukunftsperspektive äußern.

\section{I: Denkst du oft über deine Zukunft nach?}

„Ja, darüber, wie ich mir ein besseres Leben ermöglichen kann. Aber das geht halt nicht anders, es ist so, wie es ist." (männlich, 17, Afghanistan)

I: Du hast gesagt, dass du eine handwerkliche Ausbildung machst. Gefällt dir die Ausbildung?

„Ich habe keine andere Wahl, und es ist besser als nichts.“ (männlich, 16, Syrien)

- Auch die Jugendlichen im Mindset Blending In stimmen zu, dass das Thema Berufsorientierung wichtig ist. Die meisten von ihnen nennen Bildung auch als Grundwert. Weniger als die Hälfte dieser Befragten findet, dass Karriere oder Erfolg besonders wichtig sind im Leben. Die meisten haben aber eine positive Zukunftsperspektive und gehen davon aus, dass die Zukunft in ihren eigenen Händen liegt, weil die Lebensbedingungen in Deutschland gesichert und politisch stabil sind.

„Hier kannst du alles aus dir machen, es hängt nur von dir ab. Deine Menschenrechte werden eingehalten. Alles, was du dir wünschst, ist hier." (männlich, 17, Eritrea)

„Ich kann, wenn meine Noten gut genug sind, hier machen, was ich mag. Ich habe also Chancen auf jeden Beruf, wenn ich dranbleibe." (weiblich, 14, Syrien) 


\subsection{Berufswünsche}

\section{Die meisten jungen Geflüchteten nennen Berufe, die sie sich für sich vorstellen können.}

Auf die Frage, welche Berufe sie gerne ergreifen möchten, haben die Jugendlichen in der Regel eine Antwort. Nur in wenigen Fällen haben die Befragten noch keine Idee. Die große Gruppe derer, die bereits konkretere Berufswünsche haben, unterteilt sich etwa zur Hälfte in diejenigen, die nur einen einzigen Berufswunsch angeben, und diejenigen, die neben ihrem bevorzugten Berufswunsch noch Alternativen anführen. In der folgenden Tabelle sind besonders häufig gewählte Berufe fett markiert. Häufig als Alternativen bezeichnete Berufe sind mit einem Stern (*) gekennzeichnet.

Diese berufsspezifische Aufzählung macht Folgendes deutlich:

- Außergewöhnliche Berufswünsche werden nur selten genannt (z. B. Fußballer von den Jungen und Popstar von Jungen und Mädchen). Generell wählen viele der befragten Jugendlichen Berufe mit guten Arbeitsmarktchancen. Eine starke „Bodenhaftung“ ist für sie typisch bei der Planung der eigenen Bildungsbiografie.

- Bestimmte Berufe sind bei jungen Geflüchteten beliebter als andere. Dazu gehören insbesondere Berufe, die ihnen durch ihr alltägliches Leben vertraut sind.

- Die Berufswünsche fallen geschlechtsspezifisch aus. Unabhängig von ihrem Alter streben die meisten Frauen eine Karriere an, für die ein Hochschulstudium erforderlich ist. Viele der jungen befragten Frauen geben Ärztin als Wunschberuf an, gefolgt von Anwältin, Bauingenieurin, Chemikerin und Journalistin. Die weiblichen Befragten, die einen Ausbildungsberuf anstreben, bevorzugen den sozialen, medizinischen und Dienstleistungssektor (Flugbegleiterin, Friseurin, pharmazeutisch-technische Assistentin).

- Die Mehrheit der befragten geflüchteten Jungen verfolgt Berufswünsche, für die eine duale Berufsausbildung erforderlich ist: insbesondere Kfz-Mechatroniker, Bankkaufmann und Automobilkaufmann. Diejenigen männlichen Gesprächspersonen, die ein Hochschulstudium anstreben, interessieren sich hauptsächlich für Ingenieurwissenschaften, Informatik und andere technische Gebiete.

- Die Planung der weiteren Bildungsbiografie hängt mit der besuchten Schulform und dem Geschlecht zusammen. Jungen und Mädchen, die auf einem Gymnasium sind, möchten später auch studieren. Die meisten der befragten Jungen, die eine Vorbereitungsklasse besuchen oder die mittlere Reife anvisieren, tendieren zu einer Berufsausbildung. Unabhängig von der besuchten Schulform erwähnen viele Mädchen, dass sie die Schule gerne mit dem Abitur abschließen möchten. 


\begin{tabular}{|c|c|c|}
\hline $\begin{array}{l}\text { Berufsbereich (Vgl. } \\
\text { Bundesagentur für Arbeit } \\
\text { 2011) }\end{array}$ & Nennungen Mädchen & Nennungen Jungen \\
\hline $\begin{array}{l}\text { Rohstoffgewinnung, } \\
\text { Produktion, Fertigung (22) }\end{array}$ & -- & $\begin{array}{l}\text { Kfz-Mechatroniker (12), } \\
\text { Flugzeugtechniker (2), } \\
\text { Elektroniker (2), } \\
\text { Elektromechaniker (1), Ingenieur } \\
\text { (1), Maschinenbauingenieur (1), } \\
\text { Zerspanungsmechaniker (1), } \\
\text { Lackierer (1), Tischler (1) }\end{array}$ \\
\hline $\begin{array}{l}\text { Gesundheit, Soziales, Lehre und } \\
\text { Erziehung (21) }\end{array}$ & $\begin{array}{l}\text { Ärztin (11), Arzthelferin (1), } \\
\text { Krankenschwester (1), } \\
\text { Friseurin (1), Lehrerin (1), } \\
\text { Zahnärztin* }\end{array}$ & $\begin{array}{l}\text { Friseur (3), Krankenpfleger (1), } \\
\text { Medizinischer Fachangestellter } \\
\text { (Augenarzt) (1), Arzt (1), } \\
\text { Chirurg*, Lehrer*, Erzieher*, } \\
\text { Zahntechniker*, Zahnarzt* }\end{array}$ \\
\hline $\begin{array}{l}\text { Kaufmännische } \\
\text { Dienstleistungen, } \\
\text { Warenhandel, Vertrieb, Hotel } \\
\text { und Tourismus (14) }\end{array}$ & $\begin{array}{l}\text { Apothekerin oder } \\
\text { Pharmazeutisch-technische } \\
\text { Assistentin (2), Bankkauffrau } \\
\text { (1), Versicherungskauffrau* }\end{array}$ & $\begin{array}{l}\text { Bankkaufmann (4), } \\
\text { Automobilkaufmann (3), } \\
\text { Pharmazeutisch-technischer } \\
\text { Assistent (1), Hotelfachmann (1), } \\
\text { Fitnesskaufmann (1), } \\
\text { Restaurantfachmann (1), } \\
\text { Bankdirektor*, Fußballer*, } \\
\text { Koch*, Einzelhandelskaufmann* }\end{array}$ \\
\hline $\begin{array}{l}\text { Naturwissenschaft, Geografie, } \\
\text { Informatik (9) }\end{array}$ & $\begin{array}{l}\text { Informatikerin (1), Chemikerin } \\
\text { (2), Astronautin * }\end{array}$ & Informatiker (6), Geologe* \\
\hline $\begin{array}{l}\text { Verkehr, Logistik, Schutz und } \\
\text { Sicherheit (6) }\end{array}$ & $\begin{array}{l}\text { Flugbegleiterin (2), Polizistin } \\
\text { (1), Pilotin* }\end{array}$ & $\begin{array}{l}\text { Polizist (3), Mitarbeiter im } \\
\text { Geheimdienst*, Militär* }\end{array}$ \\
\hline Bau, Architektur, Vermessung, & Bauingenieurin (1) & $\begin{array}{l}\text { Anlagenmechaniker (1), } \\
\text { Architekt (1), Gerüstbauer* }\end{array}$ \\
\hline
\end{tabular}

\section{Etwa die Hälfte der Befragten hatte bereits im Herkunftsland Interesse an bestimmten Berufen.}

Knapp die Hälfte der befragten jungen Geflüchteten hatte bereits vor der Flucht Interesse an bestimmten Berufen oder Berufsfeldern, die sie in der Regel auch nach der Ankunft in Deutschland beibehalten haben. 
„Von klein auf träume ich davon, Ärztin zu werden.“ (weiblich, 14, Syrien)

„Ich wollte schon immer Ingenieur werden. In Afghanistan habe ich Informationstechnologie gelernt, und ich wollte in Europa Ingenieur werden." (männlich, 17, Afghanistan)

„Schon als Kind habe ich mich oft mit Maschinen beschäftigt. Auch die Herstellung von Stahl und Elektrizität interessiert mich sehr." (männlich, 17, Irak)

Einige der Befragten sagen, dass sie vor der Flucht nach Deutschland zu jung waren, um sich schon ernsthaft über ihre Berufsplanung Gedanken zu machen. Andere erklären, dass ihre beruflichen Möglichkeiten im Herkunftsland durch die schlechte wirtschaftliche Situation und den Mangel an Chancen stark eingeschränkt waren. Die meisten Jugendlichen betonen, dass die Aussicht auf eine Ausbildung oder ein Studium in Deutschland ihnen bislang nicht für möglich gehaltene Karriereoptionen eröffnet.

„Ich hatte damals noch keine Vorstellung von meiner beruflichen Zukunft. Ich war erst in der 6. Klasse." (männlich, 17, Syrien)

„Ich wollte früher mal irgendetwas Sportliches machen, aber das waren Kinderträume, und ich wusste nicht genau, was ich machen wollte. Mittlerweile bin ich mir sicher, was ich will“. (weiblich, 14, Syrien)

„Früher wollte ich gerne Schauspielerin werden, aber das hat sich geändert. Ich habe gemerkt, dass ich einen ,richtigen' Job anstreben sollte." (weiblich, 14, Syrien)

„In Afghanistan war nicht einmal sicher, ob ich überhaupt eine Zukunft besitze. Da gibt es auch wenig Arbeit. Die Zukunft dort ist ungewiss." (männlich, 16, Afghanistan)

„Früher dachte ich, dass ich wert- und nutzlos bin. Jeder aus meiner Gegend meinte, dass aus mir nichts wird, da mein Vater gestorben ist." (männlich, 17, Afghanistan)

\section{Differenzierung nach Mindset}

Bildungs- und Karriereziele (z. B. der Wunsch, Arzt zu werden) sind wichtige Indikatoren für die Werteorientierung der Befragten. So wurden z. B. denjenigen Befragten, die eine tertiäre Bildung anstreben und ihren beruflichen Erfolg priorisieren, Werte wie „Leistung,“ „Ehrgeiz“ usw. zugeschrieben. Eine Analyse dieser Werte nach Mindsets zeigt deutliche Unterschiede zwischen den Gruppen: 
- Die Jugendlichen im Mindset Moving Up streben hochkarätige Karrieren an. Fast alle befragten jungen Frauen und rund die Hälfte der jungen Männer in dieser Gruppe hoffen auf einen Studienplatz an einer Universität. Die andere Hälfte der männlichen Befragten strebt eine hochqualifizierte Ausbildung an. Bei den jungen Frauen nennen fast die Hälfte Ärztin als Berufswunsch, andere wollen Anwältin, Bauingenieurin oder Polizistin werden. Auch die jungen Männer nennen verschiedene prestigeträchtige und/oder gut bezahlte Berufe, darunter Architekt, Anwalt, Apotheker, Bankkaufmann, Industriedesigner und Ingenieur.

- Bei den Jugendlichen im Mindset Breaking Free fällt es schwer, sie entsprechend ihrer Karriereziele zu charakterisieren. Die Perspektiven richten sich gleichermaßen auf ein Studium an einer Universität wie auf eine qualifizierte Ausbildung, jeweils mit einem großen Spektrum an Berufswünschen. Viele dieser Berufe werden auch von Befragten anderer Mindsets genannt: z. B. von den Mädchen Apothekerin und Ärztin, von Jungen wie Mädchen Bankkauffrau/ Bankkaufmann und von den Jungen Informatiker, Mechaniker und Ingenieur. Einige Berufe scheinen aber spezifisch für die Gruppe Breaking Free zu sein: Einige wenige Mädchen des Mindsets Breaking Free nennen z. B. Chemikerin, Journalistin oder Flugbegleiterin.

- Die Jugendlichen des Mindset-Typs Holding On, die fast alle männlich sind, streben meist nach Ausbildungen in geschlechtertypischen Berufen wie Automobilkaufmann, Elektroniker, Kfz-Mechatroniker oder Lackierer. Einige äuBerten Interesse an einer Polizei- oder Militärkarriere (obwohl sie wissen, dass die deutsche Staatsbürgerschaft dafür Voraussetzung ist).

- Auch die Jugendlichen im Mindset Blending In sind überwiegend männlich und streben meist Ausbildungen in Facharbeiter-Berufen an. Etwa die Hälfte der jungen Männer nannte Kfz-Mechatroniker als ihre erste Berufswahl. Zu den anderen Top-Optionen gehören klassisch männliche Berufe wie Tischler/ Schreiner und Automobilkaufmann. Aber auch Berufe wie Restaurantfachmann/Koch, Krankenpfleger, Fitnesskaufmann und Friseur werden genannt. Die wenigen jungen Frauen in diesem Mindset haben Berufe wie Friseurin, Raumausstatterin und Informatikerin im Visier - oder auch Ärztin, eine Karriere, die von den weiblichen Befragten insgesamt am häufigsten genannt wird. 


\subsection{Motive der Berufswahl}

Die jungen Geflüchteten begründen die Auswahl ihrer Wunschberufe mit einem breiten Spektrum an Motiven. Diese lassen sich in Anlehnung an eine Kategorisierung des Bundesministeriums für Bildung und Forschung (BMBF) in extrinsische, intrinsische und sicherheitsbezogene Motive unterscheiden:

- Intrinsische Motive bündeln innere Beweggründe für den anvisierten Beruf (z. B. altruistische Motive, Interesse am Fachgebiet, Selbstverwirklichung).

- Extrinsische Motive heben hingegen auf soziale und ökonomische Nutzenerwartungen ab (Prestige des Berufs in der Bevölkerung oder der Peer Group, Verdienstmöglichkeiten).

- Sicherheitsbezogene Motive fokussieren die Zukunftssicherheit des Jobs.

Eine Studie des Instituts für Arbeitsmarkt- und Berufsforschung (IAB) identifiziert im Rahmen einer qualitativen Studie fünf Kernmotive für den Bildungserwerb bei Geflüchteten ab 18 Jahren (Brücker et al. 2016c, 33):

1. Bildung als Schlüssel zur eigenen Existenzsicherung

2. Bildung als Schlüssel zu Anerkennung und sozialer Wertschätzung

3. Bildung als Voraussetzung für weiterführende Berufsausbildungen

4. Bildung als Grundlage, um ein „,normales“ Leben führen zu können

5. Bildung als Wert an sich

Um die Berufswahlmotive der befragten Jugendlichen systematisch und vergleichbar erfassen zu können, wurde die oben beschriebene BMBF-Klassifizierung durch die vom IAB identifizierten Kernmotive ergänzt. Die zentralen Berufswahlmotive der befragten Geflüchteten werden im Folgenden auf Basis dieses Schemas beschrieben.

\subsubsection{Intrinsische Motive}

Insgesamt legen die befragten Jugendlichen mehr Wert auf intrinsische als auf extrinsische bzw. sicherheitsbezogene Motive. Die intrinsischen Motive spiegeln sich in verschiedenen Aspekten wider. 


\section{Fachinteresse und Freude am Beruf sind unabhängig vom Herkunftsland zentrale Berufswahlgründe.}

Fast alle befragten Jugendlichen nennen Interesse am Berufsfeld als ein wichtiges Berufswahlmotiv. Ungefähr die Hälfte erklärt dabei, sich schon im Herkunftsland, also vor der Flucht, für bestimmte Berufe interessiert zu haben. Eine weitere zentrale Berufswahlmotivation ist Freude am Beruf. Hier nennen die Jugendlichen vor allem soziale Kontakte, $\mathrm{Spa}$ am Lösen von Problemen sowie mathematische und technische Aspekte als zentrale Faktoren. Die beiden zuletzt genannten Punkte wurden vor allem - aber nicht nur - von jungen Männern erwähnt, die sich für MINT-Berufe interessieren. Auch einige der geflüchteten jungen Frauen, die sich für medizinische Berufe und Jobs im Ingenieurswesen interessieren, nennen technische Aspekte als Berufswahlmotivation.

Einige Befragte heben explizit hervor, dass es ihnen wichtig ist, eine „saubere“ bzw. „hygienische“ Arbeit zu verrichten. In manchen Fällen wird dies auch indirekt verdeutlicht, z. B. indem betont wird, keine Jobs im Sanitär- oder Instandhaltungsbereich in Erwägung zu ziehen.

Unter den befragten Jugendlichen, die sich für den medizinischen Sektor, die Sicherheitsbranche und bestimmte akademische Berufe interessieren, spielt es eine wichtige Rolle, dass sie mit der eigenen Arbeit anderen Menschen helfen können bzw. einen gesellschaftlichen Beitrag leisten.

Einige Befragte erwähnen auch fluchtspezifische Beweggründe bei der Berufswahl: etwa sich selbst zu beweisen, es trotz schwieriger Umstände in Deutschland schaffen zu können, anderen Geflüchteten helfen zu können und die beruflich erworbenen Kompetenzen später dem Herkunftsland zur Verfügung stellen zu können. 


\begin{tabular}{|c|c|}
\hline Intrinsische Motive & Berufswunsch und Zitate \\
\hline Spaß, Interesse & 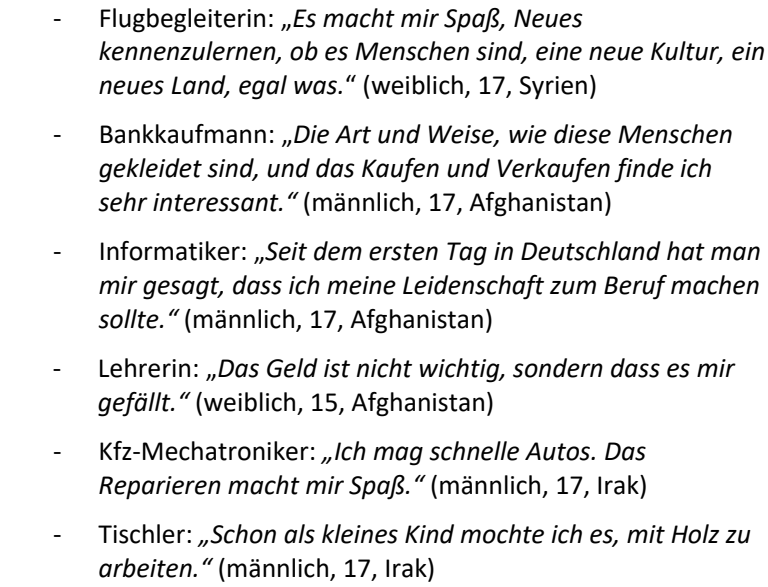 \\
\hline Soziale Kontakte & 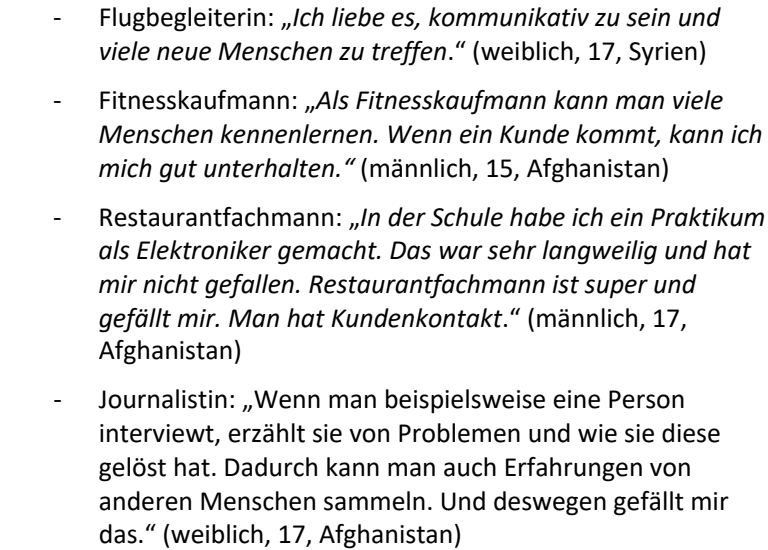 \\
\hline
\end{tabular}




\begin{tabular}{|c|c|}
\hline Umgang mit Technik & $\begin{array}{l}\text { - Luftfahrttechniker: „Ich mag Elektronik und Reparaturen } \\
\text { ausführen.“ (männlich, 16, Syrien) } \\
\text { - } \quad \text { Industriedesigner: „Ich interessiere mich für alles, was mit } \\
\text { Technik zu tun hat.” (männlich, 17, Afghanistan) } \\
\text { - Informatiker: „Ich habe ein starkes Interesse an } \\
\text { Computertechnik, Software und Applikationen.“ } \\
\text { (männlich, 17, Afghanistan) } \\
\text { - } \quad \text { Kfz-Mechatroniker: „Ich bin der beste Schüler in Technik. } \\
\text { Der Lehrer sagt, dass ich weiter dranbleiben sollte. Ich } \\
\text { interessiere mich auch sehr für Technik.“ (männlich, 16, } \\
\text { Afghanistan) } \\
\text { - Zerspanungsmechaniker: „Die Maschinen und das } \\
\text { Programmieren dieser Maschinen finde ich sehr } \\
\text { interessant. In Deutschland funktioniert vieles über } \\
\text { Maschinen und Programme. Technische Dinge gefallen mir } \\
\text { sehr.“ (männlich, 17, Afghanistan) } \\
\text { Informatiker: „Ich möchte eines Tages ein eigenes } \\
\text { Betriebssystem entwickeln.“ (männlich, 17, Afghanistan) } \\
\text { - Ärztin: „Ich mag die medizinischen Instrumente, mit denen } \\
\text { Ärzte arbeiten. Das Herz von jemandem abzuhören, finde } \\
\text { ich wahnsinnig spannend.“ (weiblich, 14, Afghanistan) }\end{array}$ \\
\hline $\begin{array}{l}\text { Geringe physische } \\
\text { Belastung, Hygiene }\end{array}$ & 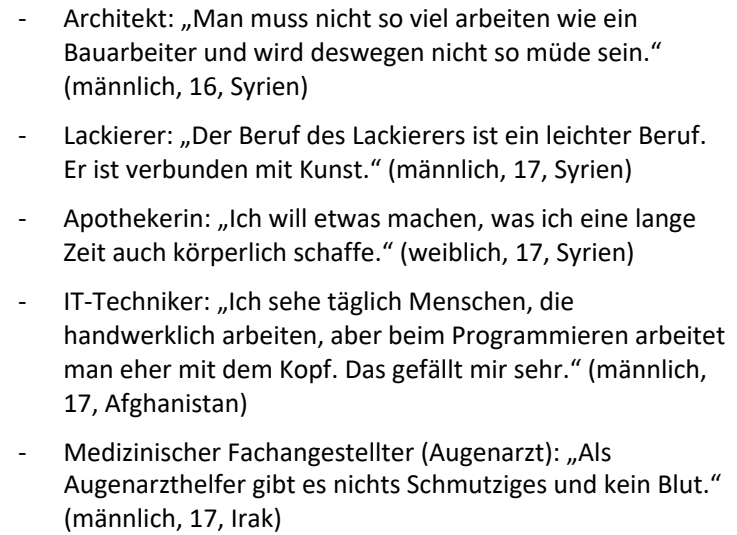 \\
\hline
\end{tabular}




\begin{tabular}{|c|c|}
\hline $\begin{array}{l}\text { Gerechtigkeit und } \\
\text { Verantwortung }\end{array}$ & $\begin{array}{l}\text { - Polizist: „Das Schöne daran ist, dass man als Polizist } \\
\text { zwischen den Unterdrückten und den Unterdrückern } \\
\text { unterscheidet.“ (männlich, 15, Syrien) } \\
\text { - } \quad \text { Ärztin: „Wie schön es sein muss, dass sich nach langem } \\
\text { Leiden eines Menschen ein Lächeln auf seinen Lippen } \\
\text { entwickelt, weil man ihm geholfen hat.“ (weiblich, 14, } \\
\text { Syrien) } \\
\text { - } \quad \text { Anwältin: „Anwälte kämpfen dafür, dass niemand zu } \\
\text { Unrecht bestraft wird. Sie lassen die Wahrheit ans Licht } \\
\text { kommen.“ (weiblich, 14, Syrien) } \\
\text { - Krankenschwester: „Ich fand den Beruf der } \\
\text { Krankenschwester immer bewundernswert, weil sie } \\
\text { anderen Menschen helfen. Ich will Menschen treffen, ihre } \\
\text { Krankheiten untersuchen und solche Sachen. Das ist ein } \\
\text { schöner Beruf.“ (weiblich, 17, Syrien) } \\
\text { - Polizist: „Als Polizist kann man den Menschen etwas } \\
\text { zurückgeben. Es ist ein verantwortungsvoller und schwerer } \\
\text { Beruf.“ (männlich, 17, Afghanistan) } \\
\text { - Polizist: „Der Polizist, der das Land beschützt - das ist } \\
\text { etwas Schönes.“ (männlich, 15, Irak) }\end{array}$ \\
\hline $\begin{array}{l}\text { Höherqualifizierung } \\
\text { und beruflicher } \\
\text { Aufstieg }\end{array}$ & $\begin{array}{l}\text { - Informatiker: „Informatiker haben eine gute berufliche } \\
\text { Zukunft, weil sie in ihrem Bereich noch vieles } \\
\text { weiterentwickeln können.“ (männlich, 16, Syrien) } \\
\text { - } \quad \text { Pharmazeutisch-technischer Assistent: „,Wenn man nach } \\
\text { der dreijährigen Ausbildung noch einige Jahre } \\
\text { weiterarbeitet, dann erlangt man in der Zeit weiteres } \\
\text { Wissen und könnte eigentlich eine eigene Apotheke } \\
\text { eröffnen.“ (männlich, 17, Syrien) } \\
\text { - Bankkaufmann: „Jetzt möchte ich erst mal Bankkaufmann } \\
\text { werden, und dann kann ich immer noch ans Studieren } \\
\text { denken, um Bankdirektor zu werden.“ (männlich, 16, } \\
\text { Syrien) } \\
\text { - Arzthelferin: „Ich will nach der Ausbildung studieren. Ich } \\
\text { mache die Ausbildung nur wegen des Abschlusses, und um } \\
\text { die Sprache besser zu lernen. Ich will vielleicht Psychologie } \\
\text { studieren, wenn ich das schaffe.“ (weiblich, 17, } \\
\text { Afghanistan) } \\
\text { Medizinischer Fachangestellter (Augenarzt): „Vielleicht } \\
\text { studiere ich nach der Ausbildung zum Augenarzthelfer } \\
\text { noch und werde Arzt.“ (männlich, 17, Irak) }\end{array}$ \\
\hline
\end{tabular}




\begin{tabular}{|c|c|}
\hline $\begin{array}{l}\text { Fluchtspezifische } \\
\text { Berufsmotive: } \\
\text { - } \quad \text { Stolz, dass man es } \\
\text { trotz } \\
\text { Schwierigkeiten } \\
\text { beruflich zu etwas } \\
\text { bringen kann } \\
\text { - } \quad \text { anderen } \\
\text { Geflüchteten } \\
\text { helfen } \\
\text { „Brain Gain“ bei } \\
\text { Remigration }\end{array}$ & $\begin{array}{l}\text { - } \quad \text { Kfz-Mechatroniker: „Ich wäre sehr stolz, als Geflüchteter } \\
\text { etwas zu erreichen.“ (männlich, 16, Syrien) } \\
\text { - } \quad \text { Hotelfachmann: „Ich mache das für mich, aber auch für } \\
\text { meine Mutter. Ich möchte, dass sie stolz auf mich ist. Wir } \\
\text { haben unsere Heimat verlassen und sind ins Ausland } \\
\text { gegangen, dort möchte ich etwas aus mir machen.“ } \\
\text { (männlich, 16, Syrien) } \\
\text { - } \quad \text { Anwältin: „,Viele Geflüchtete werden von Anwälten um ihr } \\
\text { Geld gebracht. Das ist schon so vielen hier passiert. Das } \\
\text { motiviert mich noch mehr, diesen Beruf auszuüben. } \\
\text { Nachdem ich im Heim war und so viele schlechte Anwälte } \\
\text { getroffen habe, wollte ich es unbedingt besser machen.“ } \\
\text { (weiblich, 14, Syrien) } \\
\text { - Informatiker: „Ich kann mir vorstellen, nach einiger Zeit } \\
\text { nach Afghanistan zurückzukehren, um das Land dann nach } \\
\text { vorne zu bringen.“ (männlich, 16, Afghanistan) } \\
\text { Ärztin: „Wenn es bis zum Ende meiner Ausbildung noch } \\
\text { Krieg im Irak gibt, dann würde ich hierbleiben. Aber ich } \\
\text { möchte gerne den Kindern im Irak helfen.“ (weiblich, 14, } \\
\text { Irak) } \\
\text { Apothekerin: „Ich stelle es mir sehr schön vor, dem } \\
\text { eigenen Land zu helfen und die Leute zu unterstützen.“ } \\
\text { (weiblich, 17, Irak) } \\
\text { Kfz-Mechatroniker: „Ich werde erst einmal den } \\
\text { Integrationskurs beenden, danach werde ich zur Schule } \\
\text { gehen und eine betriebliche Ausbildung beginnen. Das ist } \\
\text { auch eine Erweiterung meines Wissens. Selbst wenn ich } \\
\text { wieder nach Eritrea zurückgehe, kann ich das Wissen } \\
\text { weitergeben und lehren.“ (männlich, 17, Eritrea) }\end{array}$ \\
\hline
\end{tabular}

\subsubsection{Extrinsische Motive}

Extrinsische Motive werden oft zunächst (demonstrativ) als nachrangige Berufswahlgründe genannt. In der Gesamtschau der Interviews zeigt sich aber, dass das Ansehen des Berufs und die Verdienstmöglichkeiten von zentraler Bedeutung sind.

\section{Fast allen Befragten ist es wichtig, dass ein Beruf ein gutes Ansehen genießt.}

Nur für wenige der befragten Jugendlichen spielt es keine Rolle, ob der anvisierte Beruf gesellschaftlich ein gewisses Ansehen hat oder nicht. Den meisten ist dies 
hingegen wichtig - vor allem den Jugendlichen, die Berufe anstreben, die ein Studium voraussetzen. Sie gehen auch davon aus, dass die Wunschberufe dieser Anforderung gerecht werden.

\section{Finanzielle Absicherung ist für die meisten ein wichtiges Berufswahlmotiv.}

Etwa jeder fünfte Befragte (vor allem Jungen) äußert unmissverständlich, dass ein hohes Einkommen bei der Berufswahl entscheidend ist. Etwa ein Drittel (vor allem Mädchen) behauptet hingegen, dass das Gehalt bei der Berufswahl überhaupt keine Rolle spielt. Die restlichen Befragten liegen zwischen diesen Positionen. Für sie geht es vor allem darum, ein finanziell abgesichertes Leben führen zu können.

\section{Viele junge Männer betonen gute Einkommensmöglichkeiten, um ihren familiären Verpflichtungen nachkommen zu können.}

Die Verdienstmöglichkeiten als entscheidender Faktor bei der Berufswahl werden häufiger von jungen Männern als von jungen Frauen genannt. Unter den befragten Geflüchteten wurde das Einkommen aber nicht als Wert an sich thematisiert, sondern als notwendige Voraussetzung für den Wunsch, der eigenen Familie ein gutes Leben bieten zu können. Hier spiegelt sich auch der Befund, dass es für viele der befragten jungen Männer klar ist, dass sie sich künftig als das Familienoberhaupt sehen.

„Die Frau sollte die Aufgaben zu Hause übernehmen, und der Mann übernimmt die Aufgaben in Bezug auf Geld verdienen." (männlich, 17, Irak)

„Meine Frau muss nur die Arbeiten im Haushalt erledigen, und ich mache alles andere." (männlich, 17, Syrien).

„Die Frau sollte die Ehre der Familie wahren und dem Mann zuarbeiten.“ (männlich, 17, Afghanistan)

Eine weitere daran anschließende Motivation ist der Wunsch (bei manchen auch der soziale Druck), die im Herkunftsland verbliebene Familie finanziell zu unterstützen. Mit dieser Notwendigkeit begründen einige Befragte den Wunsch, so schnell wie möglich eine duale Ausbildung zu beginnen.

\section{Für einige der jungen Geflüchteten sind familiäre Traditionen ein Berufswahlmotiv.}

Einige der Befragten, darunter mehr Jungen als Mädchen, sympathisieren mit dem Gedanken, in der Familie verankerte Berufe aufzugreifen - weil man so die Familie stolz machen kann. 


\begin{tabular}{|c|c|}
\hline Extrinsische Motive & Typischer Berufswunsch und Zitate \\
\hline $\begin{array}{l}\text { Ansehen des } \\
\text { Berufs/Prestige }\end{array}$ & 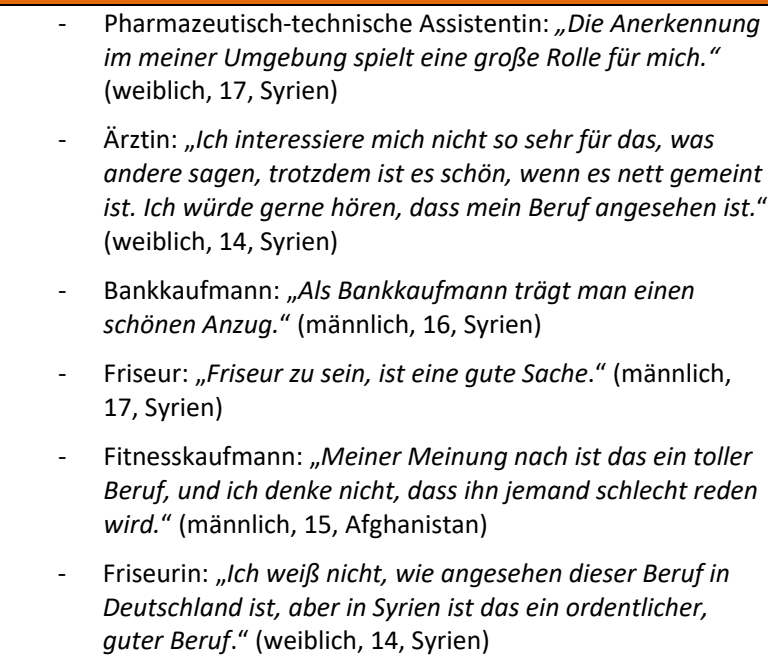 \\
\hline $\begin{array}{l}\text { Verdienst und sozialer } \\
\text { Status }\end{array}$ & $\begin{array}{l}\text { - Kfz-Mechatroniker: „Man kann gut Geld verdienen, die } \\
\text { Arbeit ist nicht so schwer und man kann eines Tages einen } \\
\text { tollen Wagen fahren. Ich möchte reich werden und ein } \\
\text { gutes Leben aufbauen.“ (männlich, 16, Afghanistan) } \\
\text { - } \quad \text { Arzthelferin: „Je mehr Geld desto besser.“ (weiblich, 17, } \\
\text { Afghanistan) } \\
\text { - } \quad \text { Kfz-Mechatroniker: „Ich denke, man kann damit viel Geld } \\
\text { verdienen.“ (männlich, 16, Irak) } \\
\text { - Polizist: „Unten vor dem Haus gibt es ein Café, in dem sich } \\
\text { viele reiche Araber treffen - meist Libanesen und } \\
\text { Palästinenser, die seit Längerem hier leben. Sie haben auch } \\
\text { Ferraris. Ich mag auch so ein Auto haben wie sie.“ } \\
\text { (männlich, 15, Syrien) } \\
\text { - Industriedesigner: „Ich fühle mich machtlos, wenn es um } \\
\text { Geld geht. Ich stecke oft in Geldnot. Aus diesem Grunde } \\
\text { entwickle ich viele Ideen, damit ich reich werde.“ } \\
\text { (männlich, 17, Afghanistan) }\end{array}$ \\
\hline
\end{tabular}




\begin{tabular}{|c|c|}
\hline & $\begin{array}{l}\text { - Journalistin: „Ich will auf jeden Fall einen Job haben, mit } \\
\text { dem ich richtig gut Geld verdienen kann, damit ich auch } \\
\text { richtig gut leben kann.“ (weiblich, 17, Afghanistan) }\end{array}$ \\
\hline $\begin{array}{l}\text { Unterstützung der } \\
\text { Familie }\end{array}$ & 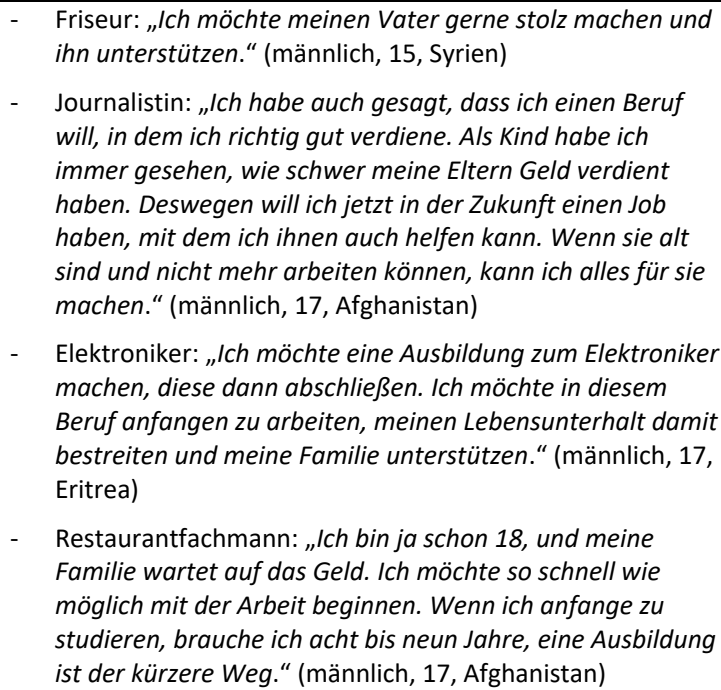 \\
\hline Familiäre Tradition & $\begin{array}{l}\text { - Ingenieur: „Mein Traum ist es, den Wunsch meines Vaters } \\
\text { zu erfüllen. Ich bin jetzt in Deutschland und kann es zu } \\
\text { etwas bringen. Ich möchte Ingenieur werden, da mein } \\
\text { Vater auch einer war.“ (männlich, 17, Afghanistan) } \\
\text { - } \quad \text { Polizist: „Mein Vater war Kommandant in Afghanistan, und } \\
\text { mein Schwager arbeitet als Polizist in Hamburg." } \\
\text { (männlich, 17, Afghanistan) } \\
\text { - Ärztin: „Meinen Eltern gefällt der Beruf auch, und mein } \\
\text { Opa war auch Arzt, deswegen will ich auch Ärztin werden." } \\
\text { (weiblich, 17, Afghanistan) }\end{array}$ \\
\hline
\end{tabular}

\subsubsection{Sicherheitsbezogene Motive}

\section{Auch sicherheitsbezogene Motive spielen eine wichtige Rolle bei der Berufswahl.}

Sicherheitsorientierte Motive spielen angesichts prekärer Lebenslagen eine wichtige Rolle bei der Berufswahl. 
- Die Möglichkeit der finanziellen und aufenthaltsrechtlichen Absicherung durch den Beruf sowie die Hoffnung, durch den Beruf ein normales und ruhiges Leben führen zu können (als Steuerzahler, mit einem Dach über dem Kopf, einer Familie und einem Auto), sind die zentralen sicherheitsbezogenen Motive bei der Berufswahl.

- Die Motivation, eine Ausbildung zu beginnen, weil sie sich auf diese Weise den Aufenthaltsstatus sichern können, wird vor allem von den afghanischen Geflüchteten angeführt.

- Einige der Befragten geben an, mit dem anvisierten Beruf überall auf der Welt Arbeit finden zu können.

- Andere wollen möglichst wenig Zeit bei der Berufsausbildung verlieren. Sie entscheiden sich daher pragmatisch - auch wenn der Wunschberuf dann (zunächst) nicht ergriffen werden kann.

\begin{tabular}{|c|c|}
\hline $\begin{array}{l}\text { Sicherheitsbezogene } \\
\text { Motive }\end{array}$ & Typischer Berufswunsch und Zitate \\
\hline $\begin{array}{l}\text { Relativ niedrige } \\
\text { Eintrittsbarrieren, } \\
\text { keine Zeit verlieren }\end{array}$ & $\begin{array}{l}\text { - Restaurantfachmann: „Ich möchte Lehrer werden. Aber } \\
\text { Lehramt zu studieren, dauert zu lange. Daher interessiert } \\
\text { mich am ehesten die Ausbildung zum } \\
\text { Restaurantfachmann.“ (männlich, 17, Afghanistan) } \\
\text { - } \quad \text { Schreiner: „Wenn ich jetzt keine Ausbildungsstelle zum Kfz- } \\
\text { Mechatroniker finde, würde ich mich zum Schreiner } \\
\text { ausbilden lassen. Der Schreinerbetrieb, in dem ich das } \\
\text { Praktikum gemacht habe, hat mich gefragt, ob ich bei } \\
\text { ihnen ausgebildet werden möchte. Ich habe ihnen } \\
\text { mitgeteilt, dass eine Ausbildung zum Kfz-Mechatroniker } \\
\text { meine erste Wahl ist, aber mir auch die Ausbildung bei } \\
\text { ihnen gefallen würde. Ich habe für den Fall zugesagt, dass } \\
\text { ich keine Ausbildungsstelle zum Kfz-Mechatroniker finde.“ } \\
\text { (männlich, 17, Eritrea) }\end{array}$ \\
\hline $\begin{array}{l}\text { Krisensicherheit des } \\
\text { Berufs }\end{array}$ & $\begin{array}{l}\text { - Bankkaufmann: „Ich denke, dass der Beruf sehr sicher ist. } \\
\text { Und wenn doch mal irgendetwas sein sollte, dann mache } \\
\text { ich halt eine andere Ausbildung in der Körperpflege." } \\
\text { (männlich, 16, Syrien) }\end{array}$ \\
\hline
\end{tabular}




\begin{tabular}{|c|c|}
\hline & $\begin{array}{l}\text { - Kfz-Mechatroniker: „Mein Vater sagt, ich soll } \\
\text { Automechaniker werden oder etwas mit Elektroautos } \\
\text { machen. Das sind Berufe mit Zukunft.“ (männlich, 16, } \\
\text { Syrien) } \\
\text { - } \quad \text { Apothekerin: „Der Beruf ist krisensicher. Krank wird man } \\
\text { immer.“ (weiblich, 17, Syrien) } \\
\text { - } \quad \text { Friseurin: „Es gibt immer Menschen, die schön aussehen } \\
\text { wollen.“ (weiblich, 14, Syrien) } \\
\text { - Polizistin: „Man braucht immer jemanden, der für Ordnung } \\
\text { sorgt.“ (weiblich, 14, Syrien) } \\
\text { - Informatiker: „Mein Ansprechpartner im Praktikum hat } \\
\text { gesagt, dass man diesen Beruf überall auf der Welt } \\
\text { ausüben kann. Auch wenn ich in Deutschland keine Stelle } \\
\text { finden würde, würde ich woanders mit Sicherheit eine } \\
\text { finden.“ (männlich, 17, Afghanistan) }\end{array}$ \\
\hline $\begin{array}{l}\text { Sicherer } \\
\text { Aufenthaltsstatus }\end{array}$ & 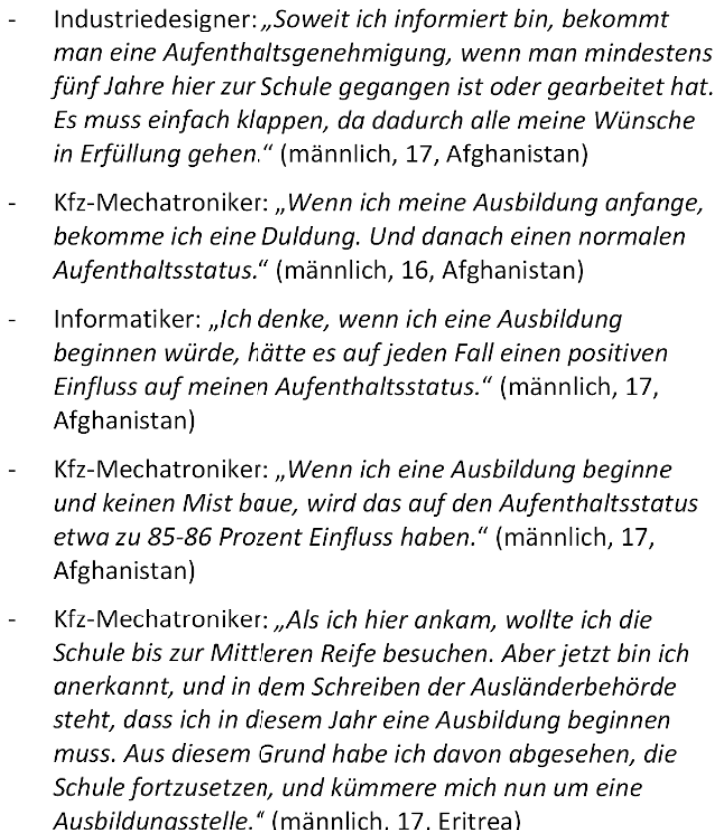 \\
\hline
\end{tabular}




\begin{tabular}{|c|c|}
\hline $\begin{array}{l}\text { Ein „,normales“ Leben } \\
\text { führen können }\end{array}$ & $\begin{array}{l}\text { - Bankkaufmann: „Das, was ich als Ziel vor Augen habe, ist, } \\
\text { eine gute Arbeit zu finden und ein ruhiges Leben mit einer } \\
\text { tollen Arbeit und einer tollen Familie zu führen.“ (männlich, } \\
\text { 17, Afghanistan) } \\
\text { - Zerspanungsmechaniker: „Ich möchte selbstständig sein } \\
\text { und mein Leben in den Griff kriegen. Momentan arbeite ich } \\
\text { und zahle meine Steuern und meine Miete. Das, was übrig } \\
\text { bleibt, reicht gerade so. Also ich habe ein gutes Gefühl.“ } \\
\text { (männlich, 17, Afghanistan) } \\
\text { - Tischler: „Es ist ein normaler, handwerklicher Beruf.“ } \\
\text { (männlich, 17, Irak) } \\
\text { Kfz-Mechatroniker: „Ich will ein glückliches Leben führen, } \\
\text { mit Arbeit und ohne Sorgen. Ich will heiraten und ein } \\
\text { glückliches Leben mit Familie führen, ohne Druck und } \\
\text { Kummer. Ein vollständiges Leben eben, mit einem } \\
\text { Aufenthaltsstatus, der mir das Arbeiten erlaubt, sodass ich } \\
\text { meinen Lebensunterhalt bestreiten kann.“ (männlich, 17, } \\
\text { Eritrea) }\end{array}$ \\
\hline
\end{tabular}

\subsubsection{Prozesscharakter der Berufswahl}

\section{Viele der jungen Geflüchteten balancieren verschiedenste Berufswahl- motive pragmatisch aus. Auch diejenigen, die vor allem intrinsische Berufswahlmotive nennen, sind zu Kompromissen bereit.}

Bei allen Befragten zeigt sich, dass die Berufswahl ein Prozess ist, bei dem verschiedene Motive zusammenspielen und miteinander abgewogen werden. Fast alle Interviewten erwähnen Fachinteresse und Freude am Beruf als dominante Berufswahlgründe. Während aber einige das intrinsische Motiv des genuinen Interesses am Beruf für sich als Grundvoraussetzung bei der Berufswahl betrachten, beschreiben andere dieses Motiv eher als nachrangig. Sie betonen ihre Bereitschaft, (zunächst) pragmatisch vom Wunschberuf abzuweichen, wenn sich dadurch Zeit sparen lässt und sie schneller finanziell unabhängig bzw. materiell abgesichert werden.

„Ich wollte früher Zahnärztin werden, aber jetzt mag ich viel lieber Apothekerin werden, weil ich es mir cooler vorstelle und der Weg zur Zahnärztin viel zu lange für mich ist." (weiblich, 17, Syrien)

„Früher habe ich daran gedacht, Arzt zu werden. Ich habe aber zu viel verpasst, weil ich nicht zur Schule gehen konnte. Man muss dafür viel mehr lernen. Ich habe nur bis zur 7. Klasse die Schule besucht. Jetzt habe ich fünf Jahre verloren. “ (männlich, 17, Syrien) 
„Als ich jünger und noch in Syrien war, wollte ich Pilotin werden, ich wollte auch noch studieren. Ich bin jetzt schon 17 und muss noch einiges in der Schule nachholen. Wenn ich dann auch noch studiere, dann werde ich ja nie fertig. Und ich will jetzt lieber Stewardess werden. Früher hatte ich die Hoffnung, mein Studium anzutreten, also ich habe meine Hoffnungen heruntergeschraubt." (weiblich, 17, Syrien)

Auch erklären einige der Befragten, dass sie von ihrem Traumberuf absehen, weil ihnen der Weg dorthin zu anstrengend erscheint, um ihn zu realisieren.

\begin{abstract}
„Ich habe schon mal bei einem Theater in der Schule mitgemacht. Ich war gut. Ich wollte auch gern eine Ausbildung zum Schauspieler machen. Aber dann habe ich mich informiert und weiß jetzt, dass das zu schwer ist. Man muss perfekt Deutsch sprechen, schreiben und lesen können. Als ich das erfahren habe, fand ich das zu schwer." (männlich, 17, Irak)

„Im Irak ist es leichter, an einer Privatuni Medizin zu studieren. Hier ist das Niveau höher, und das medizinische Bildungssystem ist anders. Ich überlege oft, einen eigenen Laden aufzumachen. Dann würde ich eine Ausbildung als pharmazeutisch-technische Assistentin machen und einen eigenen Laden aufmachen und dann vielleicht später studieren." (weiblich, 17, Irak)
\end{abstract}

Viele der befragten jungen Männer nehmen eine pragmatische Einschätzung ihrer Möglichkeiten vor. Einige von ihnen geben an, dass sie lieber eine Hochschule besucht hätten, derzeit eine duale Ausbildung aber der realistischere Weg sei bzw. ihnen nichts anderes übrig bliebe.

„Von klein an wollte ich Chirurg werden. Aber das hat sich mit der Zeit geändert. Dann habe ich an Automechaniker gedacht. Nun fiel die Wahl auf Friseur. Ich fand die anderen Berufe doch etwas zu schwer für mich." (männlich, 15, Syrien)

„Eigentlich möchte ich kein Mechaniker werden, aber das ist besser als gar nichts. Als ich ankam, wollte ich mich schulisch gerne weiterbilden, anstatt eine Ausbildung zu machen. Jetzt muss ich die Ausbildung weitermachen." (männlich, 16, Syrien)

„Ansonsten hat mir auch noch Journalist sehr gefallen, aber da muss man studieren, und ich denke, dass das dann sehr schwierig ist. Daher mag ich Bankkaufmann sehr." (männlich, 17, Afghanistan)

Einige Befragte stellen klar, dass sie mit ihren pragmatischen Kursänderungen bei der Berufsorientierung nicht glücklich sind. Sie arrangieren sich aber damit, weil sie das Gefühl haben, dass ihnen letztlich auch nichts anderes übrig bleibt. Andere 
wiederum sind weniger enttäuscht, weil sie davon ausgehen, dass sich eigene Interessen auch ändern können bzw. sie sich für Alternativen begeistern lassen können. Für diese Jugendlichen scheint es wichtiger zu sein, hart (an sich) zu arbeiten und sich für Neues zu öffnen, als den bisherigen Träumen zu folgen.

Einige der befragten Jugendlichen betrachten die erste Berufswahl als einen Kompromiss - besonders dann, wenn sie sich gegen ein Studium und für eine Ausbildung entschieden haben. Viele sehen die eigene Berufsbiografie als längerfristigen Prozess, bei dem ein Studium zu einem späteren Zeitpunkt auf die Ausbildung aufsetzt. Bei der ersten Berufswahl geht es ihnen strategisch darum, einen $\mathrm{Fuß}$ in das anvisierte Berufsfeld zu bekommen. Welche Schritte vonnöten sind, um den Wunschberuf zu einem späteren Zeitpunkt zu erreichen bzw. die Karriereleiter nach oben zu klettern, ist den Jugendlichen dabei jedoch oft nicht klar.

„Ich habe die Arbeit als Krankenpfleger gesehen. Ich habe ein Praktikum gemacht, und das hat mir gefallen. Ich möchte gerne Arzt werden, aber ich weiß noch nicht, was ich dafür nach der Ausbildung machen muss. " (männlich, 17, Syrien)

„Ich hätte gerne Informationen darüber, wie die Ausbildung eines Zahntechnikers oder Zahnarzthelfers ist und wie man es schaffen kann, nach der Ausbildung dann doch Zahnarzt zu werden. “ (männlich, 17, Afghanistan)

„Neben der Arbeit möchte ich das Abitur machen, sodass ich danach direkt ein Studium beginnen kann. “ (männlich, 17, Irak)

„Ich könnte mir auch vorstellen, zuerst eine Ausbildung zu machen und danach zu studieren. Das wäre für mich nur dann eine Option, wenn ich nach der 10. Klasse nicht auf ein Gymnasium komme." (weiblich, 17, Irak)

\section{Intrinsische, extrinsische und sicherheitsbezogene Motive gehen oft miteinander einher.}

Die folgenden Beispiele illustrieren das komplexe Zusammenspiel intrinsischer, extrinsischer und sicherheitsbezogener Berufswahlmotive. So betonen einige Jugendliche, die einen gut bezahlten oder prestigeträchtigen Job anstreben, dass die soziale Anerkennung des Berufs durch dessen gesellschaftliche Relevanz gerechtfertigt ist.

„Die Tätigkeit als Ärztin ist ehrenvoll und für die Menschen sehr hilfreich.“ (weiblich, 14, Syrien)

„Bankkaufmann ist ein Beruf, in den großes Vertrauen gesetzt wird. Die Menschen halten sehr viel von diesem Beruf, es ist eine anspruchsvolle und gute Arbeit." (männlich, 17, Afghanistan) 
Auf ähnliche Weise zeigt sich, dass diejenigen Befragten, die die Verdienstmöglichkeiten bei der Berufswahl hervorheben, sich oft gleichzeitig von materialistischen Einstellungen distanzieren und betonen, lediglich zu wollen, dass sich das Gehalt proportional zur Leistung entwickelt. Häufig erklären sie auch, das Einkommen nicht als Wert an sich zu verstehen, sondern als Voraussetzung für ein gutes Leben - insbesondere mit der Familie. Einige Befragte mit ambitionierten Karriereabsichten beschreiben ein hohes Einkommen als „Nebeneffekt" und nicht als primäres Berufswahlmotiv.

„Die Welt haben die so erschaffen, dass wir ständig Geld verdienen müssen. Dagegen können wir nichts tun. Und solange ich zufrieden bin und meine Probleme lösen kann, ist es gut.“ (männlich, 17, Afghanistan)

„In meinem Praktikum wurde mir gesagt, dass man als Programmierer sehr gut verdient. Ich habe mich noch nicht so sehr um das Gehalt gekümmert, da programmieren, wie gesagt, meine Leidenschaft ist und ich es weniger wegen des Geldes mache." (männlich, 17, Afghanistan)

„Mit reichlich Geld kann man entspannter leben.“ (männlich, 17, Afghanistan)

„Natürlich spielt das Geld auch eine Rolle im Leben. Dann kann ich auch meine Eltern unterstützen.“ (männlich, 17, Irak)

\section{Differenzierung nach Mindset}

Insgesamt orientiert sich die Berufswahl der Befragten an Werten wie Unabhängigkeit, soziale Anerkennung und familiäre Verantwortung, die das Zusammenspiel von intrinsischen, extrinsischen und sicherheitsbezogenen Motiven übergreifend prägen. Die Mischung dieser Motivlagen ist individuell sehr unterschiedlich, folgt aber dennoch bestimmten Grundmustern. Dementsprechend werden auch hier einige Unterschiede zwischen den verschiedenen Mindsets sichtbar:

- Der Großteil der Befragten im Mindset Moving Up ist stark erfolgsorientiert. Erfolgsorientierung umfasst dabei sowohl extrinsische als auch intrinsische Motivationen: einerseits Prestige, Status und Verdienst, andererseits aber auch gesellschaftliche Bedeutung, Verantwortung und Herausforderungen. All diese Ziele und Beweggründe beeinflussen die Berufswahl dieser Jugendlichen.

„,Mir gefällt ein Beruf, der Probleme löst. Ich möchte keine Berufe ausüben, bei denen man putzt oder Ähnliches. Damit bewegt man nichts. Ich möchte etwas Anspruchsvolles machen und Großes leisten.“ (männlich, 17, Afghanistan) 
„Ich möchte erfolgreich sein und einen berühmten Namen haben. Am wichtigsten ist mir, dass mich die Mädchen mögen." (weiblich, 17, Irak)

„Ein Ingenieur hat ein eigenes Ansehen.“ (männlich, 17, Irak)

„Ein gutes Gehalt ist mir wichtig.“ (männlich, 17, Afghanistan)

„Der Anwalt verteidigt die Menschen, die Hilfe brauchen.“ (männlich, 17, Syrien)

- Auch die meisten Jugendlichen im Mindset Breaking Free sind erfolgsorientiert und haben teilweise ähnliche Berufsmotive. Allerdings spielt der Wunsch nach Selbstverwirklichung in dieser Gruppe eine größere Rolle, Aspekte wie Geld und Prestige treten hingegen deutlich in den Hintergrund.

„Wenn ich daran denke, einer kranken Person etwas zu geben, was ihr helfen könnte, dann werde ich sehr glücklich und möchte noch mehr diesen Traum verwirklichen." (weiblich, 17, Syrien)

„Ich denke mir, es ist egal, was ich verdiene. Ich würde sogar ehrenamtlich arbeiten, wenn ich so Menschen helfen könnte. Das Geld kommt und geht, es hat für mich keinen Wert. Nur Bildung hat Wert für mich." (weiblich, 14, Syrien)

- Für die Jugendlichen in den Mindsets Holding On und Blending In ist Karriere und beruflicher Erfolg kein Wert an sich, sondern die Voraussetzung für stabile Verhältnisse und ein gutes Leben, für die Gründung einer eigenen Familie und die Unterstützung der Herkunftsfamilie. Das Motiv, durch den Beruf Ansehen zu erwerben, ist bei diesen Jugendlichen weniger von Prestige getrieben als vielmehr auf Normalität, Seriosität und Anständigkeit gerichtet.

„Man bleibt als Autohändler sauber, verdient ehrliches Geld und muss sich nicht so sehr sorgen" (männlich, 17, Irak)

„Ich würde gerne eine Zukunft haben wie die Deutschen. Also beispielsweise machen die Deutschen einmal im Jahr Urlaub. Sie sehen eine andere Welt. Der Deutsche hat ein Auto, eine Wohnung, Ehefrau und Kinder.“ (männlich, 15, Syrien)

„Die Hauptsache ist, dass es ein guter Beruf ist, wie z. B. Kfz-Mechatroniker.“ (männlich, 16, Syrien)

„Tischler ist ein normaler, handwerklicher Beruf.“ (männlich, 17, Irak) 


\subsection{Kenntnisse über das Bildungs- und Ausbildungssystem}

\section{Dass es in Deutschland ein bewährtes duales Ausbildungssystem gibt, ist für einige junge Geflüchtete eine neue und interessante Information.}

Aus den Interviews mit den jungen Geflüchteten geht hervor, dass sich die Bildungssysteme in den Herkunftsländern deutlich vom deutschen Bildungssystem unterscheiden und die Geflüchteten daher oft nicht wissen, welche Möglichkeiten ihnen in Deutschland offenstehen. Auch fehlen ihnen unmittelbare Bezugspersonen, die das deutsche Bildungssystem durchlaufen haben. Einige beschreiben das Wissen um die Möglichkeiten hier daher nicht nur als neu, sondern auch als „lebensverändernd“".

„In meiner Heimat habe ich über den Beruf nie nachgedacht. Ich habe nicht daran gedacht, überhaupt nach Deutschland zu kommen. Meine Ankunft in Deutschland war wie eine zweite Geburt für mich." (männlich, 16, Syrien)

„So viel ich weiß, gibt es in Syrien gar keine Ausbildungen. So etwas gab es nur für Soldaten." (weiblich, 14, Syrien)

„Was anders ist, ist, dass es in Syrien keine Ausbildung gibt.“ (weiblich, 17, Syrien) „In Afghanistan gibt es keine Ausbildung. Es gibt nur ,Drecksarbeiten““” (männlich, 16, Afghanistan)

\section{Die Mehrheit der jungen Geflüchteten fühlt sich schlecht über die Einzel- heiten des deutschen Bildungs- bzw. Ausbildungssystems informiert.}

Unter allen Befragten ist unbestritten, dass Bildung und Ausbildung bzw. die Auseinandersetzung mit der Berufswahl für die individuellen Zukunftschancen von enormer Bedeutung sind. Auch blicken die meisten jungen Geflüchteten positiv in ihre berufliche Zukunft. Gleichzeitig erklärt die Mehrheit jedoch, über das Thema Berufswahl nicht hinreichend Bescheid zu wissen.

Selbst unter den Jugendlichen, die eine Berufsausbildung anstreben, haben die meisten höchstens rudimentäre Vorkenntnisse über das Ausbildungssystem. Das gilt im Besonderen für Jugendliche, die derzeit eine Vorbereitungsklasse besuchen. Dort sind sie bislang nach eigener Auskunft nicht mit dem Thema Berufsorientierung in Berührung gekommen.

„Ich kenne noch nicht alle Regeln hier in Deutschland.“ (männlich, 15, Syrien)

„Ich weiß fast nichts darüber.“ (weiblich, 17, Irak)

„Ich verstehe das ganze Ausbildungssystem nicht.“ (weiblich, 17, Irak) 
„Ich bin nicht gut informiert. Ich habe eigentlich keine Ahnung. Ich weiß auch nicht viel über den Beruf der Krankenschwester. Ich habe keine Informationen." (weiblich, 17, Syrien)

„Warum die Ausbildung dual genannt wird, habe ich jetzt von dir erfahren. Darüber haben wir hier in der Schule noch nichts gelernt." (männlich, 17, Eritrea)

Unter den Jugendlichen, die im regulären Schulbetrieb sind, hat die Mehrheit zwar einige Fakten zur Berufsausbildung erhalten, an systematischen und gründlichen Informationen mangelt es ihnen nach eigener Auskunft aber. So wissen sie in vielen Fällen lediglich, dass die Ausbildungszeit zwei bis drei Jahre beträgt, dass Berufsschule und betriebliche Praxis verknüpft werden und dass die Ausbildungsvergütung jährlich gestaffelt ist.

„Es gibt Ausbildungen, die dauern drei Jahre. Manche dauern zwei Jahre. Wenn man die Ausbildung gut abschließt, dann kann man von der Firma übernommen werden. Oder man bildet sich weiter. Ich habe einige Informationen, aber es fehlen mir noch ein paar." (männlich, 16, Syrien)

„Ja, ich weiß, dass die Ausbildung drei Jahre dauert. Ich weiß auch, dass man im ersten Jahr ein geringeres Gehalt hat. Im zweiten Jahr erhöht sich das und im dritten Jahr erhöht es sich noch einmal.“ (männlich, 17, Syrien)

„Wenn man die Ausbildung anfängt, ist der praktische Teil immer höher als der schulische Teil. Das finde ich gut." (männlich, 17, Afghanistan)

Die wenigen Befragten, die konkrete Zahlen zur Ausbildungsvergütung genannt haben, liegen selten richtig mit ihren Angaben. Insbesondere die jungen Männer über- oder unterschätzen die finanzielle Vergütung im Rahmen der Ausbildung bei Weitem.

\section{Junge Geflüchtete, die studieren möchten, sind teilweise noch schlechter informiert über ihre beruflichen Möglichkeiten.}

Einige Befragte mit hohen Bildungs- und Karriereambitionen sind teilweise noch weniger über die Anforderungen und Rahmenbedingungen der anvisierten Berufe informiert als diejenigen mit eher moderaten Ambitionen. Das trifft vor allem auf diejenigen Befragten zu, die sich primär für Berufe interessieren, die allgemein bekannt sind und ein hohes gesellschaftliches Ansehen genießen (z. B. Arzt).

„Ich glaube, man braucht den Realschulabschluss, um Arzt zu werden.“ (männlich, 17, Syrien) 
„Ich weiß nur, dass es Ausbildungen gibt und dass man studieren kann. Und irgendwie dauert hier die Schullaufbahn länger als in Syrien. Bei uns in Syrien kommt man mit 18 in die Universität, und mit 22 könnte man schon Ärztin sein." (weiblich, 17, Syrien)

„Ich habe nicht viele Informationen zum Beruf des Journalisten. Ich denke darüber vielleicht eine Stunde in der Woche nach." (weiblich, 14, Afghanistan)

„Ich informiere mich über den Arztberuf meist im Internet, da die Lehrer das auch nicht so genau wissen. Ich denke da nicht viel darüber nach." (weiblich, 17, Afghanistan)

Der vergleichsweise geringe Wissensstand der Jugendlichen mit Studierabsichten beim Thema Berufsorientierung kann verschiedene Gründe haben. Manche der befragten Geflüchteten weisen darauf hin, vor allem Informationen zur dualen Ausbildung und weniger zur tertiären Bildung zu erhalten.

„Ich will keine Ausbildung machen, aber meine Lehrerinnen sagen mir immer, ich muss eine Ausbildung machen, etwas anderes ist nicht möglich." (weiblich, 15, Afghanistan)

„Die Lehrer versuchen, uns mehr dazu zu motivieren, eine Ausbildung anzufangen. Sie sagen, dass es besser ist und wir schneller eine Stelle finden würden. Aber ich will keine Ausbildung machen. Doch ich werde sehen. Wenn der Unterricht wirklich schwieriger wird, dann muss ich vielleicht doch erst eine Ausbildung machen." (weiblich, 17, Afghanistan)

„Ich weiß nicht, warum, aber ich habe immer das Gefühl, dass die Lehrer uns immer zu einer Ausbildung überreden wollen. Sie denken, dass dies das Beste für die Araber ist." (weiblich, 16, Syrien)

„Die Schulen hier konzentrieren sich nur auf Ausbildungen.“ (weiblich, 17, Syrien)

Unter den Befragten finden sich auch Jugendliche, die die im Herkunftsland anvisierten Berufswünsche neu ausrichteten, nachdem sie sich über die beruflichen Möglichkeiten in Deutschland informiert hatten.

„Als ich in Syrien war, wollte ich Lehrer werden, weil mein Vater Lehrer war und ihn alle kannten. Ich wollte wie mein Vater werden. Aber als ich hierhergekommen bin, habe ich die Banken gesehen und dass man dort gut arbeitet. Man trägt einen schönen Anzug. Außerdem hat mir meine Lehrerin gesagt, dass man dort viel Geld verdienen kann." (männlich, 16, Syrien) 
„Früher dachte ich mir, ich werde vielleicht Ärztin. Jetzt habe ich aber die Möglichkeit, zu machen, was ich mag. Deswegen denke ich jetzt anders und will Polizistin werden." (weiblich, 14, Syrien)

In solchen Fällen wird deutlich, dass die erworbene Kenntnis um die Vielfalt der deutschen Bildungslandschaft dazu beigetragen hat, einen Beruf anzustreben, der besser zur eigenen Persönlichkeit passt. Im Fall der zitierten Syrierin zeigt sich, dass der nun auserwählte Beruf (Polizistin) zentrale Berufsmotive des ursprünglich gewählten Berufs (Ärztin) abdeckt (z. B. Menschen helfen), diese sich aber auf eine Art und Weise im Berufsalltag ausleben lassen, die besser zum eigenen Werteuniversum (Ankerwerte: Ordnung, Gerechtigkeit) und den persönlichen Stärken (Sport) passen.

\section{Dass sie sich nicht gut über das Ausbildungssystem informiert fühlen, führt nicht automatisch dazu, dass sich die Jugendlichen aktiv um mehr Wissen bemühen.}

Die Jugendlichen, die sich schlecht über das deutsche Ausbildungssystem informiert fühlen, äußern fast durch die Bank den Wunsch nach mehr Informationen allerdings nicht alle mit gleichem Nachdruck. Einige von ihnen geben an, es sei noch zu früh, um sich mit dem Thema auseinanderzusetzen:

„Ich mache das eher Schritt für Schritt. Erst mal Abschluss, dann Abi und dann alles Weitere." (weiblich, 15, Afghanistan)

„Ich bin schulisch noch nicht so weit. Ich würde mich dann in einem Jahr weiter informieren und eventuell auch ein Praktikum machen." (männlich, 17, Irak)

„Wichtig ist für mich im Moment die Schule und der Integrationskurs. Ausbildung und Arbeit kommt dann erst. Ohne den Integrationskurs kannst du hier nichts machen. Die berufliche Zukunft ist wichtig, aber sie beschäftigt mich im Moment nicht." (männlich, 17, Eritrea)

Andere wiederum setzt der geringe Wissensstand unter Druck, sodass sie die Berufsorientierung mit Angst verbinden:

„Manchmal habe ich sogar Angst, dass ich das nicht schaffe.“ (männlich, 17, Syrien)

„Momentan habe ich aus diesem Grund sehr viel Stress.“ (männlich, 17, Afghanistan) 
„Ich habe Angst vor dem Thema Berufsorientierung. Ich denke deswegen oft daran, weil ich Angst habe, den mittleren Schulabschluss nicht zu schaffen." (weiblich, 17, Irak)

\section{Differenzierung nach Mindset}

Im Gegensatz zu den meisten anderen Befragten fühlen sich viele Jugendliche im Mindset Breaking Free gut über das deutsche Bildungs- und Ausbildungssystem informiert. Dieses Mindset zeichnet sich durch intellektuelle Neugier und eine aufgeschlossene, experimentierfreudige Haltung aus. Aber auch diese Befragten würden gerne noch mehr über dieses Thema wissen. Viele haben vor, sich entsprechende Informationen durch eigene Recherche, gezielte Beratung oder Praktika zu beschaffen.

I: Wie gut fühlst du dich informiert?

„Gut. Und wenn man noch etwas wissen möchte, dann gibt es immer noch das Internet, in dem man sich informieren kann." (männlich, 16, Syrien)

I: Wie gut fühlst du dich über deine beruflichen Möglichkeiten in Deutschland informiert?

„Ich fühle mich durch eigene Recherche sehr gut informiert."

I: Welche Informationen fehlen dir? Welche Informationen wünschst du dir? Wie kann man dir helfen?

„Ich denke, ja, es fehlen einige Informationen: Was werde ich an der Universität lernen? Warum muss ich mich spezialisieren? Wie wird das alles aussehen? [...] Jetzt frage ich oft meine Lehrer über solche Dinge. Sie haben mir sehr geholfen. Auch eigene Recherche im Internet hat viel gebracht." (weiblich, 14, Syrien)

I: Du hast dich anscheinend schon genauer über die Ausbildung informiert. Wo hast du dich informiert?

„Mein Freund hatte ein Buch über Ausbildungen, und darin waren auch Informationen zur Ausbildung zum Hotelfachmann. [...] Ich muss noch ein Praktikum machen nächsten Monat." (männlich, 16, Syrien)

Die Befragten, die sich gut über ihre beruflichen Möglichkeiten im Bilde sehen, haben oft bereits konkrete Zukunftspläne oder haben praktische Erfahrungen gemacht.

Ein kleiner Teil der befragten jungen Geflüchteten zeigt sich informiert mit Blick auf das Ausbildungssystem und zuversichtlich, was die angestrebte Karriere betrifft. Einige haben sich bereits für fachspezifische Schulen entschieden oder sich 
früh auf einen Beruf festgelegt und sich auch mit den formalen Voraussetzungen dafür auseinandergesetzt.

„Ich bin jetzt in der 9. Klasse. Danach möchte ich mein Abitur machen, und danach möchte ich an der Universität Jura studieren." (männlich, 17, Syrien)

„Ich weiß, dass ich sechs Jahre allgemeine Medizin studiere und mich dann noch einmal ein paar Jahre spezialisieren muss. Dass ich dafür zur Universität muss und dass ich sehr viel dafür lernen muss. Ich weiß, dass ich gut in Physik, Chemie, Sport und Latein sein muss." (weiblich, 17, Syrien)

Andere haben im Herkunftsland oder in Transitländern praktische Erfahrungen sammeln können, an die sie mit ihrer Berufswahl anknüpfen möchten.

„Ich habe als Lackierer im Libanon gearbeitet. Ich habe das ausgesucht, weil ich darin Erfahrung habe und das dann einfach wird für mich." (männlich, 17, Syrien)

„Ich bin sehr gut im Umgang mit dem PC. Ich hatte einen Lehrgang in Syrien gehabt, seitdem sitze ich den ganzen Tag am PC. Ich habe sehr viel Ahnung davon und hoffe, später als Informatikerin zu arbeiten." (weiblich, 17, Syrien)

Praktika erfüllen das Ziel, den Jugendlichen einen alltagsnahen Einblick in den Beruf zu ermöglichen. Die befragten Jugendlichen, die Praktika absolviert haben, waren besser über entsprechende Berufe informiert. Eine intensive Auseinandersetzung mit dem Berufspanorama zeigt sich auch darin, dass die Jugendlichen spezifische Ausbildungsberufe korrekt benennen können.

\begin{abstract}
„Als wir uns einen Praktikumsplatz suchen sollten, habe ich gesagt, dass ich das gerne in einer Apotheke machen möchte. Als ich nach Deutschland kam, hatte ich schon den Wunsch, Apotheker zu werden. Als ich mit dem Praktikum angefangen habe, habe ich Informationen erhalten, wie die Ausbildung verläuft und wie viel man verdient. Es gibt PTA (pharmazeutisch-technischer Assistent) und noch etwas anderes. Ich möchte PTA werden. Das geht mit einer Ausbildung." (männlich, 17, Syrien)

„Ich habe oft Praktika gemacht. Eines davon bei Mercedes Benz als Mechatroniker und ein zweiwöchiges bei der Handwerkskammer. Daher konnte ich mich nach dem Praktikum gut für meinen Wunschberuf entscheiden." (männlich, 16, Afghanistan)
\end{abstract}

Praktika vermitteln den Jugendlichen ein konkretes Verständnis des beruflichen Alltags. Darüber hinaus geben sie häufig den Ausschlag für die Berufsentscheidung. Praktikumserfahrungen helfen den Jugendlichen aber auch dabei, be- 
stimmte Berufe für sich auszuschließen oder sich mehr über angrenzende Berufe bzw. das Berufsfeld als solches zu informieren.

„Ich habe ein Praktikum in einer Apotheke gemacht, es war aber sehr hart, weil ich jeden Tag zehn Stunden gearbeitet habe. Und das war nur ein Praktikum, nicht richtige Arbeit." (weiblich, 17, Syrien)

„,Mein Praktikum als Kfz-Mechatroniker war super. Die Arbeit ist komplex, und das gefällt mir auch. Dennoch hat mir die Arbeit im großen Ganzen nicht gefallen, da sie nicht komplett meinen Interessen entspricht. Dann habe ich noch in einem Markt gearbeitet, und dort hat mir gefallen, dass ich Menschen helfen konnte und viel Kontakt mit Kunden hatte." (männlich, 16, Afghanistan)

„Ich habe beim Zahnarzt ein Praktikum gemacht. Das war nicht meins. Man kann das ja ausprobieren, und wenn man merkt, das gefällt einem nicht, kann man ja weitersehen." (weiblich, 17, Afghanistan)

„Ich wollte früher Medizin studieren, das war mein Wunsch. Dann habe ich in einem Krankenhaus ein Praktikum gemacht. Und danach habe ich gemerkt, dass ich das nicht machen will. Jetzt wäre mein Traumjob Bankkauffrau, wenn das nicht klappt, dann Versicherungskauffrau." (weiblich, 17, Afghanistan)

„In Eritrea kannte ich den Beruf des Schreiners gar nicht. Ich sah, wie fertig gebaute Kleiderschränke angeliefert wurden, aber ich sah nie, wie sie gebaut werden. Auf den Beruf komme ich, weil ich vor zwei, drei Monaten ein Praktikum in einer Schreinerei gemacht habe, und mir gefiel die Arbeit. Ja, ich fand sie nicht schlecht. Wenn ich jetzt also keine Ausbildungsstelle zum Kfz-Mechatroniker finde, würde ich mich zum Schreiner ausbilden lassen.“ (männlich, 17, Eritrea)

\subsection{Ansprechpartner und Informationsquellen bei der Berufsorientierung}

\section{Die meisten der befragten jungen Geflüchteten wünschen sich bei der Berufsorientierung persönliche Beratung von Angesicht zu Angesicht.}

Auf die Frage, wie die Befragten sich am liebsten über das Thema Berufsorientierung informieren möchten, zeigt sich ein klares Bild: Sie bevorzugen unmittelbaren persönlichen Austausch klar gegenüber medialen Quellen (Print und Internet). Hier gelten insbesondere Personen, die in dem anvisierten Beruf arbeiten, als bestmögliche Ansprechpartnerinnen und Ansprechpartner. 
„Wenn ich etwas im Internet nachlese, dann verstehe ich das nicht so gut. Es ist besser, wenn es mir jemand persönlich erklärt, dann verstehe ich mehr." (männlich, 17, Syrien)

„Ich finde direkte Informationen von einer Person besser als Informationen im Internet.“ (männlich, 16, Syrien)

„Niemand kann solch eine Sache von alleine nach vorne bringen. Es muss immer jemand da sein, der einem hilft. “ (männlich, 17, Afghanistan)

„Ich würde mir wünschen, dass jemand mir erklärt, welche Schulen und Universitäten es gibt und was eine Ausbildung ist." (weiblich, 15, Afghanistan)

„Ich denke, ich würde auch jemanden aus dem Berufsleben fragen, wenn ich Informationen zum Beruf suche und zum Weg, wie ich dorthin komme. Also einen Arzt oder eine Ärztin." (weiblich, 14, Syrien)

Trotz der deutlichen Präferenz für persönlichen Kontakt berichten die meisten Befragten, dass sie bislang nur mit wenigen Personen über die eigene Berufsbiografie sprechen konnten. Der persönliche Austausch zum Thema findet bislang vor allem mit Eltern und Bekannten, Lehrkräften und dem Freundeskreis statt. Vereinzelt werden auch Betreuungspersonen genannt. Dies scheint unabhängig von Alter, Geschlecht, Nationalität oder Mindset zu gelten.

\section{Die Eltern sind wichtige Bezugspersonen bei der Berufsorientierung, wenngleich die Jugendlichen betonen, dass sie ihnen kaum etwas zum deutschen Ausbildungssystem sagen können.}

Die Mehrheit der Jugendlichen, die mit der Familie geflüchtet sind, wendet sich bei Fragen rund um die Berufsfindung an ihre Eltern. Für viele sind die Eltern eine Brücke zwischen dem Leben im Herkunftsland und der Gegenwart in Deutschland. Sie sind ein stabilisierender Faktor, eine wesentliche Quelle für Anerkennung, Motivation und Unterstützung. Gleichzeitig ist den Jugendlichen bewusst, dass ihre Eltern ihnen nur sehr beschränkt bei der Berufsorientierung in Deutschland helfen können. In vielen Fällen wissen die Eltern nach Meinung der Jugendlichen nicht besser Bescheid als sie selbst; bei einigen wird die Situation auch dadurch erschwert, dass ihre Eltern nicht lesen und schreiben können und der deutschen Sprache nicht mächtig sind.

„Meine Eltern helfen mir so weit sie können, aber sie haben selbst nicht genug Informationen." (männlich, 16, Syrien)

„Ich frage meine Lehrer. Meine Eltern kann ich nicht fragen, weil sie es auch nicht wissen." (weiblich, 14, Syrien) 
„Meine Eltern haben noch weniger Informationen als ich und würden mich bei jeder Entscheidung unterstützen." (männlich, 17, Afghanistan)

„Meine Eltern wissen auch nicht, wie das System hier funktioniert.“ (männlich, 16, Irak)

„Die sollten vielleicht das Lernsystem ändern. Meine Mutter z. B. ist drei Monate in einen Integrationskurs gegangen, und sie hat gar nichts gelernt. Für meine Mutter ist das noch schwieriger, weil sie Analphabetin ist." (weiblich, 15, Afghanistan)

\title{
Der elterliche Einfluss und das Engagement der Eltern bei der Berufsorientierung fällt sehr unterschiedlich aus.
}

Generell sorgen sich die Eltern der Befragten sehr um die (berufliche) Zukunft ihrer Kinder. Wie sehr sie auf diese Einfluss nehmen und sich involvieren möchten bzw. können, ist sehr unterschiedlich. Zum einen verdeutlichen die Antworten der Befragten, dass die Berufswahl mancher Jugendlicher stark von den Eltern beeinflusst oder inspiriert ist (siehe auch Kapitel 3.3).

\begin{abstract}
„Mein Vater hat mich zu diesem Beruf im Libanon gebracht.” (männlich, 17, Syrien) „Ich möchte Elektroniker werden. Das hat mir bereits in Afghanistan gefallen und ist auch der Beruf meines Vaters. Ich habe hier viel von ihm geerbt." (männlich, 17, Afghanistan)

„Der Einfluss meiner Eltern war sehr stark. Ich wollte als Kind z. B. immer Lehrerin werden. Aber ich würde gerne meinen Eltern den Wunsch erfüllen und Ärztin werden. Aber wenn ich das überhaupt nicht wollen würde, dann würden sie sich auch nicht mehr einmischen." (weiblich, 16, Syrien)
\end{abstract}

Zum anderen zeigt sich aber auch, dass einige Eltern gegen die beruflichen Vorstellungen ihrer Kinder sind - vor allem dann, wenn der Beruf eine räumliche Trennung vom Elternhaus zur Folge hat oder ihnen als zu wenig prestigeträchtig erscheint.

„Ich muss ehrlich sagen, dass meine Mutter nicht dafür ist, dass ich den Berufsweg der Flugbegleiterin einschlage, weil sie sagt, dass ich dann oft weit weg von ihr bin. Ich finde, das ist schön, ich mag es auch, wenn man sich gegenseitig vermisst, aber meine Eltern mögen das nicht.“ (weiblich, 17, Syrien)

„Meine Mutter ist gegen eine Ausbildung. Sie will, dass ich studiere. Sie sagt, dann ist dein Zeugnis deine Waffe. Mein Cousin macht aber zurzeit eine Ausbildung, deswegen unterhalten wir uns auch oft darüber." (weiblich, 17, Irak) 
Jugendliche, deren Eltern sich für das Ergreifen prestigeträchtiger Berufe stark machen, berichten nicht selten von familiärem Druck bei der Berufswahl. Besonders häufig wird erwähnt, dass sich Eltern den Arztberuf für ihre Kinder wünschen, weil dieser in der Gesellschaft sehr anerkannt ist.

„Wenn man in Syrien Arzt ist, dann ist man etwas Besonderes. Die Eltern pushen sich und sagen, dass der Sohn Arzt ist. Aber hier muss man studieren, um Arzt zu werden. Ich bin kein Mensch, der Schule mag. Ich hasse es zu lernen. In Syrien wurde ich gezwungen, zu lernen. Hier auch.“ (männlich, 17, Syrien)

„Meine Eltern wollen, dass ich Arzt werde oder Ingenieur, dass ich viel Geld verdiene. Aber ich will Elektroniker werden." (männlich, 15, Syrien)

„Ich machte in einer Rechtsanwaltskanzlei ein Praktikum, weil meine Mutter immer wollte, dass ich Rechtsanwalt werde. Aber meine Rechtschreibung ist nicht so gut, und die sechs Jahre, die man studieren muss, interessieren mich nicht so. Ich habe meiner Meinung nach genug gelernt und möchte jetzt endlich arbeiten. “ (männlich, 17, Afghanistan)

„Meine Pflegemutter sagt, ich soll Ärztin werden. Auch mein Vater meinte immer, ich muss auf jeden Fall Medizin studieren, aber Medizin ist nicht mein Fach. Ich denke nicht, dass ich das schaffen kann." (weiblich, 17, Afghanistan)

Durch diese Antworten wird deutlich, dass hohe Ansprüche an die Bildung der Kinder das Verhältnis zwischen Eltern und Jugendlichen belasten können. Dies ist besonders dann der Fall, wenn die Ansprüche der Eltern stark von den Wünschen und Einschätzungen der Kinder abweichen.

Für die meisten der befragten Jugendlichen trifft dies allerdings nicht zu. Sie berichten, dass die Eltern ihnen motivierend und unterstützend zur Seite stehen. Von den Jugendlichen, deren Eltern die Berufswahl befürworten, geben die meisten an, dass sie die Entscheidung für den Beruf letztlich alleine getroffen haben. Einige Befragte heben sogar hervor, dass sie von ihren Eltern bewusst aufgefordert wurden, die Berufswahl selbstständig zu treffen.

„Man macht die Eltern stolz mit so einem Beruf. Aber mein Vater sagt, dass ich das werden soll, was ich möchte." (männlich, 17, Syrien)

„Ich muss in seinen Augen nicht Ärztin, Anwältin oder Ingenieurin sein. Ich sollte das machen, was mir Spaß macht." (weiblich, 14, Syrien)

„Die meinten stets, dass ich meiner Leidenschaft nachgehen sollte. In Afghanistan sind Berufe wie der eines Sängers verpönt. Aber mein Vater meinte, dass ich das, was mir gefällt, durchziehen sollte.“ (männlich, 17, Afghanistan) 
„Mein Vater sagt, dass ich nicht für ihn arbeiten werde, sondern für mich selbst.“ (männlich, 16, Irak)

\section{Lehrkräfte werden von den meisten Jugendlichen als relativ gute und verlässliche Berater bei der Berufsorientierung beschrieben. Es gibt jedoch auch Jugendliche, die schlechte Erfahrungen gemacht haben.}

Neben den Eltern werden vor allem Lehrkräfte als Ansprechpartnerinnen oder Ansprechpartner bei der Berufsorientierung genannt. Circa die Hälfte der befragten Jugendlichen gibt an, hierzu in Austausch mit Lehrkräften zu stehen oder gestanden zu haben. Lehrkräfte werden von den Jugendlichen dabei in der Regel als vertrauenswürdige Quellen beschrieben - vor allem bei Themen, zu denen das Wissen der Eltern begrenzt ist. Auch Betreuungspersonen werden vereinzelt als gute Ansprechpartnerinnen und Ansprechpartner erwähnt.

„Das, was ich wissen muss, das weiß ich. Und wenn ich etwas nicht weiß, dann frage ich meine Lehrerin." (männlich, 15, Irak)

„Ich spreche nur mit meiner Lehrerin über Berufe.“ (männlich, 17, Irak)

„Ich habe ein paar Mal meine Lehrerin gefragt. Aber ansonsten frage ich niemanden." (männlich, 16, Irak)

„In der Schule kannst du nachfragen und bekommst sicher eine Antwort.“ (männlich, 17, Eritrea)

„Am häufigsten frage ich meine Lehrer. Und dann gibt es Johannes, unseren Familienbetreuer, den frage ich auch, und im Internet lese ich auch, aber das verstehe ich nicht so gut." (weiblich, 17, Afghanistan)

Auch diejenigen Jugendlichen, die sich bislang nicht mit dem Thema Berufsorientierung auseinandergesetzt haben, halten ihre Lehr- und Betreuungskräfte für vielversprechende Kontaktpersonen.

„Bisher habe ich nichts gefragt. Egal, welche Frage ich habe, ich rufe zunächst für solche Themen meinen Betreuer an." (männlich, 17, Afghanistan)

„Ich spreche mit niemandem darüber, aber ich kann immer meine Lehrer fragen.“ (weiblich, 17, Irak)

Es gibt aber auch negative Berichte von jungen Geflüchteten. Einerseits kritisieren diese, dass die Informationen einiger Lehr- und Betreuungskräfte nicht umfassend genug, irreführend oder falsch sind. Zum anderen sind einige Geflüchtete der Mei- 
nung, dass ihre Bezugspersonen vorurteilsbelastet sind bzw. sich diskriminierend verhalten.

„In der Willkommensklasse vermitteln sie uns das Gefühl, dass wir die Kleinsten sind.“ (männlich, 15, Syrien)

„In der 10. Klasse saß ein Amerikaner neben mir. Er hat Hilfe bekommen, und mir wurde die Hilfe verweigert. Als Begründung haben unsere Lehrer oft gesagt, dass wir vom Staat leben und nichts tun würden, während sie arbeiten gehen und unterrichten. Wir würden von deren Steuern leben und deshalb haben sie uns stets erniedrigt." (männlich, 17, Afghanistan)

„Zum Beispiel sagen manche Lehrer an unserer Schule, wenn sie eine Aufgabe geben: ,Für die Schüler, die Deutsch nicht als Muttersprache haben, ist die Aufgabe schwer, die brauchen mehr Zeit.' Dann sage ich: ,Okay, das ist schwer für uns, aber Sie müssen das nicht jede Minute sagen." (weiblich, 17, Afghanistan)

\section{Angebote der Arbeitsagentur sind kaum bekannt und werden daher nur selten in Anspruch genommen.}

Nur eine Minderheit der Befragten stand bislang im Austausch mit Beraterinnen und Beratern der Bundesagentur für Arbeit. Der Kontakt zur Arbeitsagentur läuft in der Regel über die Schulen. Jugendliche, die derzeit eine Vorbereitungsklasse besuchen, haben noch seltener von Kontakten zur Arbeitsagentur berichtet.

„Ich habe einen Termin mit einer Frau, die extra zu uns in die Schule kommt und uns informiert, wenn wir möchten. Ich habe mich dafür gemeldet." (männlich, 17, Syrien)

„Wenn ich Fragen zur Ausbildung habe, dann geh ich zu einer Person von der Arbeitsagentur in der Schule. Der Berater informiert sich dann und gibt uns Bescheid." (weiblich, 17, Afghanistan)

„Wir waren mit der Schule beim Berufsinformationszentrum vom Arbeitsamt. Da wurde uns erklärt, wie wir uns informieren können." (männlich, 17, Irak)

Besuche von Jobcentern sind vergleichsweise selten. Einige der Befragten waren im Zuge schulischer Veranstaltungen schon einmal da, andere wandten sich selbst an diese Stellen. Die Jugendlichen, die Kontakt hatten, zeigten sich aber sehr zufrieden: Sie fühlten sich nach dem Besuch besser informiert und waren froh, den Service genutzt zu haben. Einige halten seitdem auch Kontakt zu den Ansprechpersonen des Jobcenters. 
„Letzte Woche hatte ich einen Termin im Jobcenter. Der Termin war für mich, weil sie wissen wollten, was ich in der Zukunft werden möchte. “ (männlich, 15, Syrien)

„Dort gibt es Computer für die Information zu Ausbildungen. Mir wurde gezeigt, wie ich mich informieren kann. Ich habe mich über die Ausbildung zum Bankkaufmann informiert." (männlich, 16, Syrien)

„Momentan ist mir beim Jobcenter eine Sachbearbeiterin zugeteilt, die mir dabei hilft, Informationen zu finden. Sie ist für mich die erste Ansprechpartnerin für Berufsfragen. Ich erzähle ihr oft, was ich gerne machen würde." (weiblich, 17, Syrien)

Die Älteren der Befragten befinden sich genauso häufig im Austausch mit der Arbeitsagentur wie die Jüngeren, obwohl die Berufswahl mit steigendem Alter immer näher rückt.

\section{Geschwister, Freundinnen und Freunde, Non-Profit-Organisationen und Jugendeinrichtungen sind weitere genutzte Informationsquellen.}

Fast so häufig wie Lehrkräfte und Betreuungspersonen nennen die Jugendlichen Freundinnen und Freunde, Geschwister, den näheren Bekanntenkreis und vereinzelt auch Kontakte aus der Gemeinde als Anlaufstellen bei Fragen rund um die Berufsplanung. Insbesondere der Freundeskreis wird als wichtige Stütze beschrieben.

„Ich habe eine polnische Klassenkameradin. Sie möchte auch Architektin werden. Vielleicht machen wir später gemeinsam eine Ausbildung bei einem Architekten." (männlich, 16, Syrien)

„Meine Freunde sagen, dass PTA eine gute Wahl ist, und unterstützen mich darin.“ (männlich, 17, Syrien)

„Dadurch, dass meine Freunde mir den Beruf beschrieben haben, wurde mein Interesse geweckt" (weiblich, 17, Syrien)

Weitere (wenn auch seltener erwähnte) Anlaufstellen bei der Berufsorientierung sind Non-Profit-Organisationen, Integrationscenter und -cafés, Jugendhäuser und Sportvereine.

„In der Nähe gab es ein Café. Freitags trafen sich da alle Frauen, auch deutsche. Wir alle gingen dort hin und tranken Tee. Wir nannten es Teeküche. Da fragte ich immer nach und informierte mich. Viele erzählten, dass sie zur Schule gegangen wären und was sie gemacht hätten. Aber genaue Informationen über Ausbildung hatten sie nicht. Ich habe schon sehr häufig gefragt." (weiblich, 15, Afghanistan) 
„Die Leute in Jugendclubs wissen Dinge, die das Arbeitsamt nicht weiß. Und das Arbeitsamt hat wiederum Informationen über Dinge, die die Leute in den Jugendclubs nicht wissen. Und die haben auch kaum Zeit für jemanden." (männlich, 17, Afghanistan)

Solche Begegnungsräume werden besonders dann positiv erwähnt, wenn Jugendliche dort von Lebenswegen bzw. Bildungsbiografien anderer erfahren und sich so ein ergänzendes Bild zu den Informationen der Arbeitsagentur machen können.

\section{Über den Freundeskreis und inoffizielle Quellen werden aber auch unvollständige oder irreführende Informationen verbreitet.}

Aus einigen Interviews geht hervor, dass Informationen zur Berufsorientierung, die man über den Freundeskreis oder informelle Quellen erhalten hat, verwirrend sind bzw. nicht der Wahrheit entsprechen. Einige Befragte erhielten zum Beispiel verkürzte Informationen und fragliche Aufforderungen („Man muss nur viel lernen, dann hat man einen Job sicher").

„Mein Freund macht eine Ausbildung als Elektroniker. Er hat gesagt, dass ich erst einmal warten und weiter die Sprache lernen soll. Ich soll zudem warten, bis ich volljährig bin." (männlich, 17, Afghanistan)

„Wir werden sehr oft gefragt, was wir in der Zukunft werden wollen. Aber ich muss dann immer sagen, dass wir hier ganz neu sind. In Afghanistan gibt es das nicht. Ich weiß gar nicht, was eine Ausbildung ist. Ich habe gar keine Informationen darüber, aber ich wüsste gerne, was das ist. Wenn man die Deutschen selber fragt, dann sagen sie auch, dass sie es nicht genau wüssten. Sie erzählen dann von sich, dass sie die Schule besucht hätten, zur Uni gegangen wären und jetzt Ärzte oder Lehrer seien. Sie wissen selber nicht, was das genau alles ist." (weiblich, 15, Afghanistan)

In mehreren Antworten wird deutlich, dass sich die Jugendlichen auf unzureichende Informationen verlassen, die sie aus informellen Quellen erhalten haben (vor allem Hörensagen). Beispielsweise speist sich der Wissensstand einiger afghanischer Befragter zum Einfluss einer Ausbildung auf den Aufenthaltsstatus aus ungenauen bzw. falschen Informationen.

„Mir fehlt die Information, was man machen muss, damit man einen normalen Aufenthaltsstatus bekommt." (männlich, 17, Afghanistan)

„Man sagt, dass man definitiv eine höhere Chance auf ein Bleiberecht hat, wenn man arbeitet." (männlich, 17, Afghanistan) 
„Soweit ich informiert bin, bekommt man eine Aufenthaltsgenehmigung, wenn man mindestens fünf Jahre hier zur Schule gegangen ist oder gearbeitet hat. “ (männlich, 17, Afghanistan)

„Wenn ich meine Ausbildung anfange, bekomme ich eine Duldung. Und danach einen normalen Aufenthaltsstatus. Und wenn ich dann richtig arbeite, darf ich laut meinen Informationen nicht abgeschoben werden. Denn wer nämlich Steuern zahlt, kann nicht abgeschoben werden. “ (männlich, 16, Afghanistan)

„Noten sind mir sehr wichtig, da die Note viel aussagt und man eventuell nicht in Deutschland aufgenommen wird bei schlechten Noten." (männlich, 17, Afghanistan)

\section{Mediale Informationsquellen werden in der Regel als Ergänzung zu persönlichem Austausch herangezogen, allerdings ziehen nur wenige der Befragten mediale Quellen anderen Informationsmöglichkeiten vor.} Unter den medialen Quellen spielt das Internet bei der Aufklärung über Ausbildungsfragen die größte Rolle (vor allem Google-Suche und YouTube-Clips), gefolgt von Print-Materialien, die in der Regel über die Schule bezogen werden. Das Fernsehen wird hingegen so gut wie gar nicht erwähnt. Gerade im Vergleich zu den persönlichen Ansprechpartnerinnen und Ansprechpartnern gelten Medien lediglich als ergänzende Informationsquellen bei der Berufsorientierung.

„Mir ist es lieber, mit jemandem persönlich zu sprechen, aber wenn ich keine Person finde, mit der ich darüber reden kann, dann gehe ich ins Internet." (männlich, 15, Syrien)

„Ich recherchiere selbst im Internet. Ich würde lieber mit jemandem sprechen, aber ich kenne niemanden, mit dem ich darüber sprechen könnte." (weiblich, 17, Syrien)

„Ich würde gerne beides machen. Ich mag es, über das Thema Beruf zu lesen, ich bespreche das aber auch gerne mit jemandem zusammen. Ich denke, wenn mir das jemand erklärt, dann kann ich mir das besser merken und besser verstehen." (weiblich, 14, Syrien)

„Ich habe mich auf den Internetseiten des Arbeitsamts informiert. Ich glaube, die Seite hieß Jobbörse. Was ich nicht verstanden habe, habe ich mir ins Arabische übersetzt. Aber es wäre besser, wenn das jemand mit mir zusammen besprechen könnte." (männlich, 17, Irak)

Einige der Befragten betonen, dass sie ihre Informationen zum Beruf lieber eigenständig sammeln, ohne sich an andere Personen zu wenden. In einigen Fällen geben sie an, dass sie auf non-personale Informationsquellen zurückgreifen, weil es ihnen an Vertrauen fehlt. 
„Ich lese lieber etwas alleine, da kann ich mich konzentrieren.“ (weiblich, 14, Syrien)

„Hier in Deutschland kann man sich nicht einmal auf seinen eigenen Bruder verlassen, man sollte stets alles selber machen." (männlich, 17, Afghanistan)

„Wenn ich mich selber informiere, dann bringt es mir mehr. Alles, was man selber macht, ist besser.“ (männlich, 15, Afghanistan)

\section{Sprache gilt als zentrale Barriere im Zugang zu Informationen zur Berufsorientierung - vor allem mit Blick auf mediale Quellen.}

Die Sprachbarriere wird als größtes Problem im Zugang zu Informationen zur Berufsorientierung genannt. Aber auch zeitliche Engpässe relevanter Ansprechpartnerinnen und Ansprechpartner werden genannt. Lehrkräfte gelten unter Geflüchteten zwar als gute Informationsquellen, die Befragten stellen jedoch zum Teil auch fest, dass diese oft überarbeitet sind und sich daher nicht genügend Zeit nehmen können. In ländlichen Regionen kritisieren die Jugendlichen zudem, dass es keine entsprechende Infrastruktur für berufsorientierende Maßnahmen vor Ort gibt.

„Wenn ich etwas im Internet nachlese, dann verstehe ich das nicht so gut. Die Sprache ist noch zu schwer für mich." (männlich, 17, Syrien)

„Ich wüsste nicht einmal, was ich im Internet für einen Suchbegriff eingeben soll, um auf diese Seiten zu gelangen. Vielleicht liegt es einfach daran, dass ich meine deutsche Sprache verbessern muss." (weiblich, 15, Syrien)

„Die Lehrerin hat nicht genug Zeit, um uns alle Informationen zu geben.“ (männlich, 16, Syrien)

„Ich habe noch nicht so viele Informationen. Mein Betreuer wollte mir mal eine Zeitschrift geben, in der 366 Ausbildungsberufe beschrieben werden, und ich sollte mir einen davon aussuchen und mich darüber informieren. Bisher habe ich die Zeitschrift nicht bekommen und gelesen. Niemand kann solch eine Sache von alleine nach vorne bringen. Es muss immer jemand da sein, der einem hilft. Ich denke, dass mir auch in zwei Monaten, wenn ich erwachsen bin, keiner hilft." (männlich, 17, Afghanistan)

„Das hier ist ein sehr kleiner Ort, hier gibt es keine Möglichkeiten, wo man sich informieren könnte. In der Schule gibt es auch nur die Lehrer, und die unterrichten nur. Sie haben keine Zeit mehr, uns zu beraten. Ähnlich ist es beim Sozialamt, heißt das so?" (weiblich, 15, Afghanistan) 
Aber selbst in größeren Kommunen, die über die einschlägige Infrastruktur verfügen (Bibliotheken, Jobcenter, soziale Einrichtungen etc.), werden die Angebote teilweise nicht genutzt - in der Regel, weil sie zu weit vom Wohnort entfernt sind. Mit Blick auf mediale Quellen wird besonders die Sprachbarriere hervorgehoben. Deutschsprachige Quellen gelten als sprachlich (noch) zu kompliziert. Einige der Befragten befürchten, falsche Entscheidungen zu treffen, weil sie die Informationsmaterialen nicht richtig verstehen. Muttersprachliche Angebote sind entweder nicht vorhanden oder nicht bekannt. Die befragten Jugendlichen aus Eritrea etwa beklagen, dass es besonders auf Tigrinya keine Angebote gibt.

„Eine Bibliothek gibt es schon, aber da habe ich keine Zeit, um hinzufahren. Das ist auch viel zu weit weg, man muss zweimal umsteigen, um dahin zu kommen." (weiblich, 17, Afghanistan)

„Ich habe mich noch nicht informiert, weil ich Angst habe, etwas nicht zu verstehen oder falsche Informationen zu bekommen." (weiblich, 14, Syrien)

„Ich habe mich bisher nicht informiert, weil ich weiß, dass es lange dauert, etwas im Internet nachzulesen, und die Informationen werden sicherlich auf Deutsch sein. Es gibt deutsche Wörter, die ich nicht kenne." (männlich, 15, Irak)

„Die Araber haben Wörterbücher und Apps, mit denen sie kurz eine Übersetzung finden. So etwas gibt es für uns nicht. So etwas wäre hilfreich.“ (männlich, 17, Eritrea)

\subsection{Informationsbedarfe}

\section{Die meisten jungen Geflüchteten wünschen sich mehr berufsorientierende Informationen.}

Unabhängig davon, ob die Jugendlichen eine Ausbildung oder ein Studium anvisieren, ist der Wunsch der jungen Geflüchteten nach berufsorientierenden Informationen groß. Die Mehrheit hat sich bereits einen ersten groben Überblick über das Bildungs- bzw. Ausbildungssystem in Deutschland verschafft, dennoch sind viele noch sehr unsicher. Diese Befragten haben häufig bereits einen (vorläufigen) Berufswunsch. Eine konkrete Entscheidung haben sie aber noch nicht getroffen. Sie sind deshalb daran interessiert, zu erfahren, inwiefern spezielle Bildungspfade für sie realistisch sind, welche Fähigkeiten bestimmte Berufe voraussetzen, welche Notendurchschnitte sie mitbringen müssen und ob es Besonderheiten im Bewerbungsverfahren gibt (z. B. Vorlage von Motivationsschreiben, Mappen/Portfolios etc.). 
„Momentan weiß ich, welche Fächer mich interessieren und was ich machen kann. Bei manchen Fächern braucht man aber richtig gute Sprachkenntnisse, und darüber denke ich nach. Ich schaue bei jedem Studiengang, wie gut man Deutsch können muss, z. B. braucht man für Informatik mehr Englisch-als Deutschkenntnisse.“ (weiblich, 17, Afghanistan)

„Mich interessiert, was man für die Ausbildung braucht und wie das mit der deutschen Sprache ist. Was man lernt, wie schwer die Schule ist und was die Voraussetzungen für die Ausbildung sind." (männlich, 17, Irak)

„Ich möchte gerne wissen, mit welchen Noten man mich annehmen würde.“ (männlich, 15, Irak)

Die Jugendlichen, die sich bereits sicher sind, welchen Beruf sie ergreifen möchten, interessieren sich vor allem für konkrete Informationen über die nächsten Schritte: formale Qualifikationsanforderungen, wie sie an Praktika herankommen, was im Berufsalltag auf sie zukommt, wie die Verdienstmöglichkeiten als Auszubildende sind, wie sie sich richtig bewerben, etc.

„Ich denke, ja, es fehlen einige Informationen. Was werde ich in der Universität lernen? Warum muss ich mich spezialisieren? Wie wird das alles aussehen? " (weiblich, 14, Syrien)

„Welche Klasse muss man abschließen, und was ist der nächste Schritt? Wie kann man ein Praktikum machen, um sich die Berufe anzuschauen? “ (weiblich, 14, Irak)

„Vielleicht würde mir eine Vermittlung zu jemandem helfen, der meinen Traumjob schon ausübt. Ich weiß bis jetzt nur ungefähr, was man so macht als Polizistin. Doch viele der Aufgaben kenne ich bestimmt noch nicht. Und ich weiß noch, dass man sehr sportlich sein muss, um Polizistin zu werden, und Durchsetzungsvermögen haben muss." (weiblich, 14, Syrien)

„Ich möchte gerne wissen, wie viel man im zweiten und dritten Ausbildungsjahr verdient.“ (männlich, 17, Syrien)

„Ich würde gerne längere Praktika machen, aber wie komme ich da ran, und was mache ich da? " (weiblich, 17, Syrien)

Es gibt aber auch junge Geflüchtete, die bisher noch nichts über das Bildungs- und Ausbildungssystem in Deutschland wissen und sich auch noch keine genaueren Gedanken über einen Wunschberuf gemacht haben. Diese Befragten wollen erst einmal erfahren, welche Bildungswege und Karrierechancen im Allgemeinen und welche Berufe es im Besonderen in Deutschland gibt. Sie wünschen sich einen grundlegenden Überblick über das deutsche Bildungs- und Ausbildungssystem, inklusive der offiziellen Bezeichnungen von Schulformen und Ausbildungsgängen, 
um sich darauf aufbauend in Eigeninitiative weiter informieren und für sich die richtigen Entscheidungen treffen zu können.

„Welche Informationen mir fehlen, das weiß ich nicht. Ich habe keine Informationen.“ (männlich, 17, Syrien)

„Ich brauche vieles. Im Irak macht man nach der Schule keine Ausbildung, sondern man arbeitet sofort.“ (männlich, 17, Irak)

„Ich brauche viele Informationen, z. B. welche Ausbildung für mich die richtige ist und in welchen Bereichen man eine Ausbildung machen kann. Ich glaube, ich hätte dann auch mehr Auswahl, wo ich eventuell auch studieren kann." (weiblich, 17, Irak)

„Die reden viel darüber, aber ich verstehe das nicht. Ich will wissen, was man bei einer Ausbildung macht und was man dafür braucht, wo man eine Ausbildung machen kann und was sie beinhaltet." (weiblich, 14, Irak)

„Über die Schulen würde ich gerne mehr wissen. Ich wüsste gerne, wie das Schulsystem hier ist. Einer geht hier zur Realschule, ein anderer zur Gemeinschaftsschule. Ich weiß gar nicht, was das überhaupt ist. In Afghanistan gibt es nur eine Schule. Es gibt keine Aufteilung wie hier. Und es gibt hier auch schulische Ausbildungen. Ich möchte gerne mehr über die Schulen wissen.” (weiblich, 15, Afghanistan)

„Ich kenne den offiziellen Namen der Ausbildung nicht.“ (männlich, 16, Afghanistan)

„Ich hätte gerne eine Gesamtübersicht und einen großen Überblick über alle Informationen." (männlich, 15, Afghanistan)

\subsection{Einschlägige Erfahrungen und Kompetenzen}

\section{Viele der befragten jungen Geflüchteten kommen mit berufsrelevanten Kompetenzen nach Deutschland.}

Auf die Frage, was die Jugendlichen ihrer Meinung nach besonders gut können (bzw. was andere über ihre Talente denken), antwortet ca. ein Drittel mit Fertigkeiten, die für ihre konkreten Berufspläne relevant sind. Darunter finden sich vor allem Jungen, die technische bzw. handwerkliche Fertigkeiten angeben, aber auch einige Mädchen. 
„Ich kann gut lackieren. Ich habe auch Autos gewaschen.“ (männlich, 17, Syrien) „In handwerklichen Jobs wie zum Beispiel auf einer Baustelle, wo man viel Kraft aufwenden muss, bin ich gut. Ansonsten dann noch an Maschinen." (männlich, 17, Afghanistan)

„Im handwerklichen Bereich bin ich gut, z. B. wenn ich einen Schrank aufbaue.” (männlich, 17, Irak)

„Ich kann jetzt schon gut Haare frisieren und bekomme oft Komplimente für meine Arbeit an anderen oder an mir selbst." (weiblich, 14, Syrien)

„Ich kann sehr gut schminken und Fingernägel pflegen.” (weiblich, 17, Irak)

Ein Teil der befragten Jugendlichen hat berufsrelevante Praxiserfahrungen über Jobs im Herkunftsland oder während der Flucht in Transitländern gesammelt. Darunter sind einige, die im Rahmen regulärer Arbeitsverhältnisse für längere Zeit beschäftigt waren und die ihre Erfahrungen nun auch im Bewerbungsverfahren entsprechend nachweisen können.

„In Pakistan habe ich einmal sechs Monate im IT-Bereich als Programmierer gearbeitet." (männlich, 17, Afghanistan)

„In Afghanistan habe ich zwei Jahre als Kfz-Mechatroniker gearbeitet. Das war super. Dann habe ich damit aufgehört und bin in die Schule gegangen, bevor ich nach Deutschland gekommen bin." (männlich, 17, Afghanistan)

Andere gingen informellen oder kurzzeitigen Nebenbeschäftigungen nach. In beiden Fällen berichten die Jugendlichen, dass ihre praktischen Erfahrungen für ihre Berufsorientierung von großem Einfluss sind, sei es mit Blick auf einen spezifischen Beruf (z. B. Krankenpfleger) oder ein Berufsfeld (z. B. Interesse an handwerklichen Berufen).

„In Afghanistan habe ich für das Verlegen von Leitungen oder beim Anbringen von Gegenständen bei vielen Familien kein Geld verlangt, weil ich dadurch auch etwas gelernt habe. In Afghanistan habe ich für drei Monate Telefone zusammengebaut und für weitere zwei Monate Computer zusammengebaut." (männlich, 17, Afghanistan)

„Seitdem ich drei Jahre alt war, habe ich viele Spielzeugautos gehabt und habe sie auseinander gebaut, da ich wissen wollte, wie sie zusammengesetzt sind. Danach waren wir im Iran und mein Vater hat dort Telefone verkauft und repariert. Da war ich oft dabei und habe meinem Vater über die Schulter geschaut." (männlich, 17, Afghanistan) 
„Wir hatten in Eritrea einen Obstanbau mit künstlicher Bewässerung betrieben. Die Bewässerung wurde von Motoren angetrieben, die oft kaputtgingen. Dann beauftragte mich mein Vater immer damit, den Motor abzumontieren und in die Kfz-Werkstatt zu bringen. Und mein Vater sagte zu dem Inhaber der Werkstatt: ,Schau, wie geschickt mein Sohn mit den Schraubenziehern hantiert. Er bemüht sich auch sehr.' Der Inhaber bestätigte das, und mein Vater fädelte für mich in dieser Werkstatt einen Lehrgang im Schrauben ein.“ (männlich, 17, Eritrea)

Die meisten der Befragten wissen hingegen nicht, wie sie ihre Erfahrungen und Fertigkeiten im Rahmen der Berufsvorbereitung nutzen können, z. B. wie sie einen Lebenslauf oder eine Bewerbung schreiben, welche fachlich vergleichbaren Sektoren es in Deutschland gibt und wie diese organisiert sind, welche Firmen relevant sind usw. Sie sind sich teilweise auch nicht darüber im Klaren, dass ihre Fähigkeiten für den Arbeitsmarkt in Deutschland relevant sind.

„Ich habe als Schneider gearbeitet, aber hier gibt es keine Schneider, also kann man es vergessen." (männlich, 17, Syrien)

„Im Iran war ich ein Schneider. Hier gibt es keine Schneidereien. Hier muss man für einen Beruf eine Ausbildung machen. Im Iran stellst du dich vor und erklärst, was du alles so kannst. Und dann gehst du an die Arbeit." (männlich, 17, Afghanistan)

\section{Die Jugendlichen ziehen aus Praktika nicht nur berufsrelevante Kenntnisse, sondern auch Selbstbewusstsein.}

Ungefähr ein Drittel der Befragten hat bereits ein Praktikum absolviert oder konkrete Pläne gefasst, sich darum zu kümmern. Die Befragten, die bereits Praktika gemacht haben, stimmen darüber ein, dass sie im Rahmen des Praktikums berufsrelevante Kompetenzen vermittelt bekommen haben. Die Praktika hatten eine Länge von wenigen Tagen bis zu einigen Wochen, nur selten dauerten sie einige Monate. Meist wurden sie über die Schulen oder die Betreuungskräfte arrangiert. Aus den Gesprächen mit den Jugendlichen geht klar hervor, dass sie von der Praktikumserfahrung nicht nur fachlich profitiert haben, sondern dass diese auch ihr Selbstbewusstsein gesteigert hat.

„Ich habe ein zweiwöchiges Praktikum in einem Elektrobetrieb gemacht. Ich habe gelernt, Stromkabel zu verlegen, und war sogar in einem KiK-Geschäft dabei und habe dort viele Kabel verlegt. Und ich habe dort gelernt, dass Strom nie ausgeschaltet wird. Wenn nötig, wird alles abgeschaltet. Wenn du einen Fehler machst, kannst du davon sterben. Der Chef hat mich sehr gelobt. “ (männlich, 17, Afghanistan) 


\begin{abstract}
„Im Krankenhaus habe ich mich während eines Praktikums über die Arbeit dort informiert. Ich kann einen Kranken rechtzeitig verlegen, die Mahlzeiten pünktlich verteilen und darauf achten, wer nicht essen darf. Es gibt manche Patienten, die dürfen nicht essen, weil sie eine anstehende Operation haben." (männlich, 17, Syrien)

„Ich hatte ein Praktikum beim Schreiner. Einer der Mitarbeiter war Franzose. Er hat mir immer verboten, etwas anzufassen, und sagte, dass ich noch nichts kann. Ich habe ihm etwas im Internet gezeigt und meinte, dass ich das nachbauen möchte. Er hat das immer abgelehnt. Ich habe es aber stückweise zusammengebaut, und am Ende hat er eingesehen, dass ich das wirklich machen möchte. Das Praktikum hat mir sehr gefallen, da ich wirklich tätig war.“ (männlich, 16, Afghanistan)
\end{abstract}

Wie in Kapitel 3.4 dargelegt, sind die Jugendlichen mit Praktikumserfahrung besser über die alltäglichen Aufgaben eines bestimmten Berufes im Bilde. Praktika bieten denjenigen Jugendlichen, die außerhalb Deutschlands bereits in ähnlichen Feldern Arbeitserfahrungen sammeln konnten, auch eine bessere Vorstellung darüber, welche Fähigkeiten und Fertigkeiten übertragbar sind und wo neue Lernherausforderungen auf sie warten.

Allerdings gibt es auch einige Berichte über negative Praktikumserfahrungen. Diese betreffen vor allem Diskriminierung aufgrund der Herkunft oder religiösen Orientierung sowie Machtmissbrauch bzw. Ausbeutung.

\begin{abstract}
„,Manchmal werde ich vielleicht anders angeguckt, weil ich einen Hijab trage. Zum Beispiel war das jetzt so, als ich ein Praktikum gesucht habe. Ich wurde immer gefragt, warum ich einen Hijab trage. Das war sehr schwierig. " [Fängt an zu weinen.] (weiblich, 17, Afghanistan)

„Ich habe ein Jahr lang ein Praktikum bei einem Friseur gemacht. Jeden Tag habe ich dort von 9 bis 20 Uhr gearbeitet und kein Geld dafür bekommen. Nur an zwei Tagen war ich in der Schule und viereinhalb Tage habe ich gearbeitet, am Samstag auch. Mein Chef hat mir gesagt, dass er mir eine Ausbildung gibt, darauf habe ich gewartet. Dann kam der September, und ich habe ihn darauf angesprochen. Da hat er mir gesagt, dass er selber noch kein Meister ist. Darauf habe ich ihm gesagt: ,Willst du mich verarschen?' Seit dem Tag möchte ich kein Friseur mehr werden." (männlich, 17, Irak)
\end{abstract}

\title{
Die Jugendlichen bringen ein breites Spektrum an Kompetenzen mit.
}

Die Jugendlichen, die noch keinen praktischen Einblick in Berufe hatten, antworten auf die Frage nach ihren Stärken und Kompetenzen vor allem mit Schulfächern, in denen sie gut sind. Am häufigsten werden dabei Mathematik und Sprachen ge- 
nannt. Dabei handelt es sich um Fächer, von denen die Jugendlichen in der Regel davon ausgehen, dass sie für ihre berufliche Zukunft besonders relevant sind.

„Ich mag Mathematik sehr, und ich kann gut rechnen. Ich mag es, mit Geld umzugehen.“ (männlich, 16, Syrien)

„Ich bin gut in Mathematik, ich mag es sehr. Ich denke, das könnte mir im Studium helfen." (weiblich, 14, Syrien)

„Man muss in Mathe und logischem Denken sehr gut sein, um Zerspanungstechniker werden zu können." (männlich, 17, Afghanistan)

Neben berufspraktisch relevanten Erfahrungen und Schulfächern, in denen sie gut sind, erwähnen die Jugendlichen besonders auch sogenannte Soft Skills als persönliche Ressourcen. Hier gehen sie vor allem auf soziale Qualitäten ein.

„Meine Stärken sind, dass ich liebenswürdig bin und den Leuten helfe.“ (männlich, 16, Syrien)

„Ich habe eine gute Menschenkenntnis.“ (männlich, 17, Syrien)

„Egal wann Probleme entstehen, ich bin der Erste, der das von meinen Freunden erfährt. Ich meine Probleme zwischen meinen Freunden. Und ich bin derjenige, der die Probleme zwischen den Freunden am häufigsten löst. “ (männlich, 15, Syrien)

„,Meine Freunde sagen, dass ich schnell verzeihe und mich nicht streite. Ich habe ein gutes Herz und bin nicht nachtragend. " (männlich, 16, Syrien)

„Ich denke nicht, dass nur die Noten wichtig sind, sondern auch deine Arbeitshaltung, deine Fähigkeit in Gruppen zu arbeiten und wie freundlich und hilfsbereit $d u$ bist. In Syrien war es so, egal wie du bist, Hauptsache ist, dass deine Noten gut sind." (weiblich, 14, Syrien)

„Ich denke, ich habe ein sympathisches und offenes Auftreten. Ich bin selbstbewusst und habe viel Mut und Kraft." (weiblich, 17, Syrien)

„In Gruppenarbeiten bin ich ziemlich fit. Ob es in den Praktika war oder in der Schule, ich habe ausschließlich eine gute Resonanz bekommen. Ich soll weiter am Ball bleiben." (männlich, 17, Afghanistan)

„Ich bin oft gut gelaunt und bin jemand, der weiß, wie er mit Menschen umgeht.“ (männlich, 16, Afghanistan)

„Ich verstehe die Menschen. Ich erkenne, wenn jemand etwas auf dem Herzen hat. Ich kann gut zuhören." (männlich, 15, Irak)

Das breite Spektrum an Fähigkeiten, das die Jugendlichen benennen, spiegelt sich in den Schlüsselkompetenzen wider, die das Europäische Parlament mit Blick auf lebenslanges Lernen betont. Die Menschen benötigen diese für ihre persönliche 
Entfaltung, die soziale Integration, den Bürgersinn und die Beschäftigung (Empfehlung des Rates vom 22. Mai 2018 zu Schlüsselkompetenzen für lebenslanges Lernen).

\begin{tabular}{|c|c|}
\hline Kompetenzen & Typische Zitate \\
\hline Mehrsprachenkompetenz & $\begin{array}{l}\text { "Ich kann sehr schöne Geschichten schreiben auf Arabisch." } \\
\text { (weiblich, 17, Irak) } \\
\text { "Ich kann Kurdisch, Arabisch, Englisch, Deutsch, und hier habe } \\
\text { ich Persisch gelernt." (männlich, 16, Syrien) } \\
\text { "Ich kann meine Muttersprache Arabisch sowie Deutsch und } \\
\text { Englisch perfekt und ein bisschen Französisch." (männlich, 16, } \\
\text { Syrien) }\end{array}$ \\
\hline $\begin{array}{l}\text { Mathematische } \\
\text { Kompetenz und } \\
\text { Kompetenz in } \\
\text { Naturwissenschaften und } \\
\text { Technik }\end{array}$ & $\begin{array}{l}\text { "Ich kann Mathematik sehr gut und liebe das Lernen." } \\
\text { (männlich, 16, Syrien) } \\
\text { „Ich bin sehr stark in Biologie." (weiblich, 17, Syrien) } \\
\text { "In Mathematik kann ich richtig gut klarkommen, auch in Physik } \\
\text { und anderen Naturwissenschaften." (weiblich, 17, Afghanistan) }\end{array}$ \\
\hline Digitale Kompetenz & $\begin{array}{l}\text { „Im Iran haben meine Eltern gesagt, dass ich in } \\
\text { Computertechnik gut bin und eher in diese Richtung gehen soll. } \\
\text { Zu Hause repariere ich auch alles, wenn etwas kaputtgeht." } \\
\text { (männlich, 17, Afghanistan) } \\
\text { "Ich kann alles rund ums Handy oder um soziale Netzwerke gut." } \\
\text { (weiblich, 17, Syrien) } \\
\text { "In der Schule habe ich Technik als Vertiefung gewählt, und der } \\
\text { Lehrer ist sehr zufrieden mit mir. Ich bin der beste Schüler in } \\
\text { Technik." (männlich, 16, Afghanistan) } \\
\text { "Ich war schon immer interessiert an Programmieren und an } \\
\text { Computern. Selbst der Lehrer sagt, dass ich das sehr schnell } \\
\text { lerne, und betont, dass ich das Talent und die Leidenschaft dafür } \\
\text { habe." (männlich, 17, Afghanistan) }\end{array}$ \\
\hline
\end{tabular}




\begin{tabular}{|c|c|}
\hline $\begin{array}{l}\text { Persönliche, soziale und } \\
\text { Lernkompetenz }\end{array}$ & $\begin{array}{l}\text { "Ich lerne neue Dinge schnell. Ich habe z. B. sehr schnell Deutsch } \\
\text { gelernt." (männlich, 16, Syrien) } \\
\text { "Meine Auffassungsgabe ist schnell." (männlich, 17, } \\
\text { Afghanistan) } \\
\text { „Ich habe auch ein Talent dafür, schnell Sprachen zu lernen. Ich } \\
\text { verstehe schnell die Grammatik." (weiblich, 17, Afghanistan) } \\
\text { "Ich lerne immer, wenn es nötig ist. Manchmal informiere ich } \\
\text { mich auch im Internet zu einigen Fragen." (männlich, 17, Syrien) } \\
\text { "Afghanische Freunde, die noch nicht so lange hier sind, } \\
\text { wundern sich oft und fragen, wie lange ich schon hier bin, weil } \\
\text { ich die deutsche Sprache relativ gut beherrsche. Auch wenn es } \\
\text { eine für mich neue Tätigkeit gibt, erlerne ich diese sehr schnell." } \\
\text { (männlich, 16, Afghanistan) }\end{array}$ \\
\hline Bürgerkompetenz & $\begin{array}{l}\text { "Ich mag es gerne, mich über alles zu informieren, z. B. über die } \\
\text { Politik. Ich mag es nicht, unwissend zu sein." (männlich, 17, } \\
\text { Syrien) } \\
\text { "Ich interessiere mich sehr für Politik und weiß viel darüber." } \\
\text { (weiblich, 17, Syrien) } \\
\text { "Der Wille in mir, anderen Menschen helfen zu wollen, könnte } \\
\text { mich motivieren." (weiblich, 15, Syrien) } \\
\text { "Ich glaube, ich bin beim Thema, richtig zuhören' wirklich gut. } \\
\text { Ich habe einen starken Charakter und möchte für das Recht } \\
\text { kämpfen." (weiblich, 14, Syrien) } \\
\text { "Ich helfe meinen Eltern bei den Unterlagen und Papieren und } \\
\text { den Terminen. Das, was sie nicht können, übersetze ich dann." } \\
\text { (männlich, 17, Syrien) } \\
\text { "Ich bin gut im Helfen. Wenn meine Freunde Hilfe brauchen, } \\
\text { dann fragen sie mich." (männlich, 16, Syrien) } \\
\text { "Ich kann gut mit Menschen umgehen und bringe Menschen } \\
\text { zum Lächeln." (weiblich, 17, Syrien) } \\
\text { "Die anderen sagen, dass ich richtig gut diskutieren und richtig } \\
\text { gute Argumente finden kann." (weiblich, 17, Afghanistan) } \\
\text { "Ich interessiere mich für Politik und Organisationen. Das ist } \\
\text { etwas, was ich auch in Zukunft machen möchte." (männlich, 17, } \\
\text { Afghanistan) }\end{array}$ \\
\hline
\end{tabular}




\begin{tabular}{|c|c|}
\hline $\begin{array}{l}\text { Eigeninitiative und } \\
\text { unternehmerische } \\
\text { Kompetenz }\end{array}$ & $\begin{array}{l}\text { „Egal wie schwer und anstrengend die Arbeit ist, es kümmert } \\
\text { mich nicht. Egal wie erschöpft ich bin, ich arbeite immer bis zum } \\
\text { Ende. Ich denke, wenn ich für einen Chef gut arbeite, bekomme } \\
\text { ich eines Tages auch das Glück, gute Mitarbeiter zu finden. Ich } \\
\text { arbeite nicht nur des Geldes wegen." (männlich, 17, } \\
\text { Afghanistan) } \\
\text { "Meine Stärke ist, denke ich, dass ich bis jetzt alles, was ich } \\
\text { wollte, auch geschafft habe. Wenn ich mir richtig Mühe gebe, } \\
\text { dann kann ich das auch weiter schaffen. Deswegen finde ich, ist } \\
\text { das eine Stärke." (weiblich, 17, Afghanistan) } \\
\text { "Wenn ein Kunde kommt, kann ich mich gut unterhalten." } \\
\text { (männlich, 15, Afghanistan) } \\
\text { "Ich bringe Lust und Motivation zur Arbeit mit. Wenn ich mir } \\
\text { etwas in den Kopf setze, dann schaffe ich das." (männlich, 16, } \\
\text { Irak) }\end{array}$ \\
\hline $\begin{array}{l}\text { Kulturbewusstsein und } \\
\text { kulturelle } \\
\text { Ausdrucksfähigkeit }\end{array}$ & $\begin{array}{l}\text { „Ich mache gerne Musik, und das nimmt eine große Zeit in } \\
\text { Anspruch. Ich möchte das später gerne studieren." (männlich, } \\
\text { 16, Syrien) } \\
\text { "Ich mag YouTube und ich möchte gerne einen Channel und } \\
\text { Zuschauer haben. Früher wollte ich religiöse Lieder singen. Jetzt } \\
\text { mache ich Rap." (männlich, 15, Syrien) } \\
\text { "Ich zeichne viel, ich liebe das Zeichnen. Und ich schreibe } \\
\text { Gedichte, da brauche ich noch etwas Übung, finde ich, aber ich } \\
\text { mag es sehr. Ich denke, ich kann mich sehr gut ausdrücken. Auch } \\
\text { Gefühle kann ich sehr gut ausdrücken." (weiblich, 14, Syrien) } \\
\text { "Ich kann gut schauspielern. Ich spiele manchmal meinen } \\
\text { Freunden etwas vor oder manchmal auch nur für mich." } \\
\text { (weiblich, 14, Afghanistan) } \\
\text { "Ich mag Holz schnitzen und etwas Schönes daraus machen. } \\
\text { Manchmal lese ich ein Buch oder male." (männlich, 17, Irak) } \\
\text { "Ich mag sehrgerne zeichnen, insbesondere Mode zeichnen, und } \\
\text { ich gucke mir YouTube-Videos an, die einem das Zeichnen } \\
\text { beibringen. Ich zeichne sehr gerne Klamotten." (weiblich, 17, } \\
\text { Irak) }\end{array}$ \\
\hline
\end{tabular}

\section{Jungen benennen teilweise Aggressivität und die Mädchen mangelndes Selbstvertrauen als Schwäche.}

Viele der geflüchteten Mädchen und Jungen sind bezüglich ihrer deutschen Sprachkompetenz verunsichert. Auch zweifeln einige die eigenen mathematischen Fähigkeiten an. Dies ist mit Blick auf beide Kompetenzbereiche ein Grund für sie zur 
Sorge, denn sie heben gleichzeitig hervor, dass diese Kompetenzen in der heutigen Zeit besonders wichtig sind.

Mit Blick auf personale Kompetenzen zeigt sich ein Geschlechterunterschied: Die jungen Frauen bemängeln zum Teil fehlendes Selbstbewusstsein und emotionale Sensibilität. Die jungen Männer hingegen kritisieren an sich selbst fehlende Selbstdisziplin bzw. Selbstkontrolle - auch mit Blick auf aggressives Verhalten.

„Ich würde gerne an mir ändern, dass ich mehr rede, dass ich mir das mehr zutraue. Es gibt welche, die können richtig gut reden, aber ich kann das nicht. Ich will so sein wie die hier sind, viel selbstbewusster, und mehr reden." (weiblich, 15, Afghanistan)

„Wenn ich eine Serie anschaue, dann bin ich sehr emotional und weine manchmal, wenn jemand lacht, dann lache ich mit. Das würde ich gerne ändern, weil sie mich verrückt nennen." (weiblich, 17, Afghanistan)

„Ich würde gerne etwas an mir ändern. Manchmal benehme ich mich wie ein Kind und sage mir, du musst dich ein bisschen erwachsener benehmen. Das passiert mir oft." (weiblich, 17, Irak)

„Ich bin sehr sarkastisch, das ist eine Schwäche. Außerdem werde ich schnell aggressiv. Meine Stärke ist, dass ich lieb bin. Das sagt zumindest jeder zu mir. " (männlich, 15, Syrien)

„Meine Schwäche ist, dass ich schnell aggressiv werde, aber ich prügle mich nicht.“ (männlich, 17, Syrien)

„Meine Freunde würden sagen, dass ich gut bin, aber auch etwas aggressiv. Ich mag nicht zu viel Witz.“ (männlich, 16, Syrien)

„Meine Schwächen sind, dass ich manchmal meine Gefühle nicht unter Kontrolle bekomme und dann leicht aggressiv werde." (männlich, 16, Irak)

„Als Schwäche würde ich ansehen, dass ich es nicht mag, wenn Leute trinken und dann launisch werden oder ihre Stimmung wechselhaft wird. Ich gehe aus und trinke dann auch und ertappe mich immer wieder bei einem solchen Verhalten. Das habe ich bisher nicht in den Griff bekommen können." (männlich, 17, Eritrea)

\subsection{Bewertung des Schulsystems und Unterstützung durch die Schule}

Wie in den vorherigen Kapiteln beschrieben, ist das hiesige Bildungs- und Ausbildungssystem ein wesentlicher Grund, weshalb die allermeisten der befragten jungen Geflüchteten gerne in Deutschland bleiben möchten. Für die Mehrheit ist Bildung nicht nur ein zentraler Wert an sich, sondern die Voraussetzung für ein sicheres, stabiles und sinnvolles Leben (siehe auch Kapitel 3.1). 


\section{Die meisten sind mit der Schule zufrieden. Kritik wird vor allem an Haupt- und Realschulen geäußert.}

Ungefähr zwei Drittel der Befragten sind mit ihrer derzeitigen schulischen Situation im Großen und Ganzen zufrieden. Die anderen stehen der Schule gespalten oder unzufrieden gegenüber, und nur wenige sind sehr unzufrieden. Auffällig ist, dass die Zufriedenheit mit der Schule weder mit Geschlecht, Alter, bisheriger Dauer des Aufenthalts in Deutschland, Wohnform, Bundesland noch mit den weiteren Bildungsplänen (Ausbildung oder Studium) zusammenzuhängen scheint. Schülerinnen und Schüler der Mindset-Typen Moving Up und Breaking Free lassen oft mehr Leidenschaft für das Lernen erkennen als die anderen Gruppen. Aber auch die meisten Schülerinnen und Schüler der Gruppen Holding On und Blending In erkennen ebenso die Bedeutung der Schule und äußern sich zufrieden mit ihr. Die Zufriedenheit mit der Schule hängt dabei in vielen Fällen mit der besuchten Schulform zusammen: Während sich die meisten Schülerinnen und Schüler an Gymnasien, Berufsschulen und Vorbereitungsklassen in Summe zufrieden zeigen, ist ca. ein Drittel der Jugendlichen an Haupt- und Realschulen deutlich weniger zufrieden. Die Schülerinnen und Schüler in Vorbereitungsklassen kritisieren zwar einzelne Aspekte, sind jedoch ansonsten zufrieden.

Neben ihrem Gesamteindruck wurden die Jugendlichen in den Interviews auch gebeten, ihre Zufriedenheit mit einzelnen Aspekten der Schule mitzuteilen (Unterrichtsqualität, Austausch mit Mitschülerinnen und Mitschülern, schulische Infrastruktur, Schulleitung, außerschulische Angebote, kreative Möglichkeiten, z. B. Musik und Kunst, und Angebote zum Ausleben der eigenen Religion). Nicht alle Befragten äußerten sich zu allen Punkten, aber die meisten, die die Fragen beantworteten, bewerteten die meisten Aspekte positiv. Einzig mit der Möglichkeit, die eigene Religion ausüben zu können, sind einige unzufrieden.

\subsubsection{Zufriedenheit mit Unterricht und Lehrkräften}

\section{Die befragten Jugendlichen sehen die Schule ausschließlich als Lernort im engeren Sinne. Sie finden, dass sie dort effektiv lernen.}

Das wichtigste Kriterium bei der Einstufung der eigenen Zufriedenheit mit der Schule ist für die jungen Geflüchteten die Unterrichtsqualität (wie effektiv gelehrt wird bzw. wie viel man aus dem Unterricht für sich mitnehmen kann) sowie die sozialen Kompetenzen der Lehrkräfte. Etwa zwei Drittel der Befragten sind bezüglich der Schule zufrieden oder sehr zufrieden. Diejenigen, die sich sehr zufrieden äußern, betonen vor allem die didaktischen Fähigkeiten und die Hingabe ihrer Lehrkräfte. Im Einzelnen werden folgende Aspekte hervorgehoben: 
Sensibilität bzw. starke Bedarfsorientierung bezüglich der spezifischen Situation junger Geflüchteter, gute Unterrichtsvorbereitung, Offenheit für bzw. Geduld bei Rückfragen sowie Disziplin bzw. Autorität der Lehrkräfte (für Ruhe und Ordnung sorgen während des Unterrichts).

Einige der Befragten erklären ihre Zufriedenheit besonders vor dem Hintergrund schwieriger schulischer Verhältnisse im Herkunftsland (siehe auch Kapitel 3.1).

„Es ist angenehm, und ich kann im Unterricht gut lernen.“ (weiblich, 14, Syrien) „Ich fühle mich im Unterricht sehr wohl. Ich habe das Gefühl, dass auf meine besondere Situation geachtet wird." (weiblich, 15, Syrien)

„Ich erlebe, wie man respektiert wird und man gut gelaunt in die Schule geht. In Afghanistan haben die Lehrer schon einen Schlagstock in der Hand und geben einem Hiebe und treten einen, wenn man etwas macht, was ihnen nicht passt. So kann man nicht lernen. Manchmal frage ich mich, wie unterschiedlich die Welt doch ist." (männlich, 17, Afghanistan)

In einigen Interviews wurden die Jugendlichen gebeten, ihre Zufriedenheit mit der Schule auf einer Skala von 1 bis 10 zum Ausdruck zu bringen.

„Ich vergebe 10 von 10 Punkten. Weil ich gerne lerne und ich seit den 18 Monaten, die wir schon hier in Deutschland sind, ausschließlich gute Erfahrungen mit dem Unterricht gesammelt habe.“ (männlich, 17, Afghanistan)

„10 von 10. Die zwei Lehrer sind motivierend und gut vorbereitet.“ (männlich, 17, Eritrea)

„Die machen das sehr gut. Wenn wir etwas nicht verstehen, dann sagen wir Bescheid, damit sie das noch mal erklären, weil wir alles verstehen müssen, um die Klassenarbeiten zu bestehen. Ich würde sagen eine 10.“ (weiblich, 14, Irak)

\section{Die Sprachbarriere gilt als größtes Hindernis beim Lernen und ist daher eine zentrale Quelle für Unzufriedenheit in der Schule.}

Etwa ein Viertel der Befragten ist unzufrieden oder sehr unzufrieden mit der Schule. Der Grund hierfür ist vor allem, dass Lernfortschritte durch Sprachbarrieren beeinträchtigt werden. Abseits eigener Sprachprobleme sind viele mit der Schule zufrieden. Umso frustrierter äußern sich diese Jugendlichen darüber, nicht schnell genug Deutsch zu lernen. Besonders die Jugendlichen, die keine Vorbereitungsklassen besuchen, thematisieren das Problem, im Unterricht aus Sprachgründen oft nicht mithalten zu können. In diesem Zusammenhang weisen sie auch darauf 
hin, dass Sprachprobleme ein Grund für Marginalisierung und Diskriminierung im Schulkontext sind.

„Ich gehe lustlos zur Schule, weil ich nichts verstehe.“ (männlich, 16, Syrien) „Sie sollten vielleicht beim Alphabet anfangen. Das muss ich mir selber zu Hause beibringen. Wir sprechen ja Dari, und wir haben ein anderes Alphabet. Wir sagen alef, be, pe, te und die sagen $A, B, C, D$. Sie sollten einfach anfangen und dann erst die schwierigen Sachen durchnehmen. Wir sind gerade mal den ersten Tag da und sie sagen: das Buch, das Heft. Am ersten Tag weiß man das doch nicht." (weiblich, 15, Afghanistan)

„Der Geschichtsunterricht ist etwas anspruchsvoll, da man dafür die deutsche Sprache beherrschen muss." (männlich, 15, Afghanistan)

„Ich bin nicht so gut in Deutsch. Manchmal verstehe ich etwas nicht. Wenn ich alles verstehen könnte, wäre alles viel besser." (männlich, 17, Syrien)

„Während der Schulzeit habe ich einige Probleme mit der Sprache. Aber ansonsten ist die Schule gut." (männlich, 16, Syrien)

„Es ist alles gut, aber die Sprache ist schwierig.“ (männlich, 17, Irak)

„Wenn ich in der Klasse einen Fehler mache oder etwas falsch ausspreche, dann lachen sie mich direkt aus und machen sich lustig über mich." (weiblich, 17, Syrien)

„Es werden die gemobbt, die neu sind. Wenn sie zum Beispiel etwas falsch aussprechen, dann wird gelacht und die anderen sagen: ,Wie sprichst du denn?!' Oder sie lachen über die Kleidung und machen sich darüber lustig." (weiblich, 17, Afghanistan)

Die Schülerinnen und Schüler beklagen sich nur selten über zu strenge oder anspruchsvolle Lehrkräfte - eine Eigenschaft, die sie zum Teil sogar befürworten. Einige wünschen sich jedoch, dass die Lehrenden ihre Sprechgeschwindigkeit stärker an das Sprachniveau derer anpassen, die erst seit Kurzem in Deutschland sind.

„Eine Lehrerin redet immer zu schnell, und dann verstehe ich sie nicht.“ (männlich, 15 , Syrien)

„Die Lehrer unterrichten viel zu schnell.“ (weiblich, 17, Irak)

Viele der Befragten kritisieren, dass die sprachlichen und fachlichen Kompetenzen der Schülerinnen und Schüler innerhalb eines Klassenverbunds zu heterogen sind und einer bedarfsgerechten Beschulung entgegenstehen. Jugendliche in Vorbereitungsklassen sorgen sich hingegen häufig darum, dass gute Fortschritte beim Deutschlernen ohne täglichen Kontakt zu in Deutschland aufgewachsenen Mitschülerinnen und Mitschülern gefährdet sind. Auch sind diese Jugendlichen 
teilweise frustriert darüber, dass der Fokus primär auf dem Spracherwerb liegt und andere Fächer zunächst außen vor bleiben. Gleichzeitig gibt es aber auch Jugendliche im Regelunterricht, die sich überfordert fühlen und lieber eine Vorbereitungsklasse besuchen würden. Ein Befragter berichtet positiv über einen Wechsel in eine Vorbereitungsklasse, andere wiederum beklagen, dass ihnen der Besuch einer Vorbereitungsklasse aus Platzmangel verwehrt blieb.

„Ich war früher in einer anderen Schule in einer neunten Klasse. Dort habe ich den Unterricht in Mathematik, Naturwissenschaften, Sozialwissenschaften und auch Deutsch besucht. Aber hier lerne ich nur Deutsch. Was mich auch stört ist, dass ich die gleichen Dinge lerne, die ich schon in der vorherigen Schule gehabt habe. Sie haben mich noch nicht mal getestet, ich wurde nur in deutscher Sprache getestet, und dann haben sie mich in die Willkommensklasse gesteckt." (männlich, 15, Syrien)

„Ich war vorher in einer deutschen Klasse auf einem Gymnasium. Es waren wirklich alle sehr nett. Aber ehrlich gesagt, habe ich damals nichts verstanden. Und dann gab es sogar zusätzlich Französisch und Englisch." (männlich, 15, Irak)

„Ich besuche eine normale Klasse. Ich wollte aber am Anfang lieber nur die Sprache lernen, weil ich noch kein Deutsch kann." (weiblich, 17, Syrien)

„Sie haben mich auch aus Versehen in die falsche Klasse gesteckt. Aber ich komme nach dem Schuljahr in eine normale Klasse." (weiblich, 17, Irak)

„Das Niveau sollte gesenkt werden. Da ich in meiner Heimat die Schule bis zur 5. Klasse besucht habe, verstehe ich hier nicht so viel wie die anderen, die bis zur 10. Klasse zur Schule gegangen sind. Die Schulleitung wollte mich eigentlich zurückstufen, aber leider gab es keine freien Plätze mehr." (männlich, 16, Syrien)

\section{Es wird häufiger von struktureller Benachteiligung oder latenter Diskriminierung als von direkter Diskriminierung berichtet.}

An der fachlichen Unterrichtsqualität haben die meisten Befragten keine Zweifel. In seltenen Fällen wird aber kritisiert, dass manche Lehrkräfte junge Geflüchtete diskriminieren.

„Manche Lehrer sind ausländerfeindlich.“(männlich, 17, Syrien)

„Ich habe auch das Gefühl, dass einige mich nicht als gleichwertig betrachten. Ich fühle mich dann immer so, als wenn ich kein Mensch wäre. Als ob ich blöd wäre oder so." (weiblich, 15, Syrien)

„In der Schule sind viele Lehrer gegen Flüchtlinge. Sie helfen einem nicht bei den Hausaufgaben. [...] Ich hätte eigentlich den Hauptschulabschluss der 10. Klasse erhalten sollen, habe aber nur den der 9. Klasse. Zwei Lehrer waren der Grund dafür. 
Ich habe mich nämlich zu ihren Kommentaren gegen Flüchtlinge geäußert. Aus diesem Grund haben die mir nur diesen Hauptschulabschluss gegeben." (männlich, 17, Afghanistan)

„Es gibt Lehrer, die sind gut. Und es gibt Lehrer, die keine Ausländer mögen.“ (männlich, 17, Irak)

Ebenso selten - aber durchaus vorhanden - sind Vorwürfe der jungen Geflüchteten, dass ihre Lehrkräfte sich nicht ausreichend um sie kümmern, d. h. sie nicht angemessen fördern und ihnen kein hilfreiches Feedback geben. Einige wenige Schülerinnen und Schüler werfen ihren Lehrkräften auch vor, dass sie Migrantinnen und Migranten prinzipiell - und auf abwertende Art und Weise - ein niedrigeres Bildungspotenzial unterstellen.

„Ich habe eine Lehrerin in der Schule, deretwegen ich seit einem Jahr und neun Monaten nichts gelernt habe. Sie bringt uns bei, Teller abzuwaschen und zu putzen, obwohl wir im Sprachunterricht sind. Dann sage ich ihr immer, ich kann abwaschen und putzen. Einfach eine Katastrophe." (weiblich, 17, Irak)

„Der Lehrerin ist es völlig gleich, ob ich lerne oder ob ich nichts lerne. Sie vergibt Hausaufgaben, und es ist egal, ob du sie löst oder nicht. Sie vergibt einfach so Noten in dem Zeugnis.“ (männlich, 15, Syrien)

„Der Lehrer hat mich nie im Unterricht korrigiert. Den anderen hat er geholfen, aber mir eher nicht so. Dann habe ich Texte geschrieben. Auch die hat er leider nicht korrigiert. Egal, was ich gemacht habe, das prallt an ihm ab, und er hilft mir nicht." (männlich, 17, Afghanistan)

„Ich wünsche mir, dass die Lehrerinnen und Lehrer mich weiter motivieren und uns die nötige Anerkennung geben." (männlich, 17, Afghanistan)

Einige Jugendliche, die mit der Schule unzufrieden sind, machen nicht die Schule, sondern sich selbst dafür verantwortlich, da es ihnen an Motivation mangelt.

„Es liegt an mir selbst, ich muss an meinem Willen arbeiten.“ (männlich, 15, Afghanistan)

„Ich habe Probleme mit mir selber. Ich will nicht. Wenn ich in die Schule gehe, dann habe ich keine Gefühle. Aber wenn ich zur Arbeit gehe, dann habe ich komplett Gefühle. Ich hasse Schule nicht. Aber ich bin nicht der Mensch, der gerne lernen oder lesen will.“ (männlich, 17, Irak) 


\subsubsection{Zufriedenheit mit dem Miteinander in der Klasse}

\section{Die Mehrheit der Befragten kommt gut mit den Mitschülerinnen und Mitschülern aus.}

Die jungen Geflüchteten sind zum Großteil - über alle besuchten Schulformen hinweg - zufrieden mit dem Klassenverbund. Sie nehmen ihre Mitschülerinnen und Mitschüler als hilfsbereit, verständnisvoll, freundlich, offen und interessiert an neuen Freundschaften wahr. Einige berichten von sehr engen freundschaftlichen Beziehungen innerhalb der Schülerschaft.

„Das Miteinander ist gut. Die anderen helfen mir auch.“ (männlich, 15, Syrien)

„Ich vergebe hier 10 von 10 Punkten, weil wir uns alle gut verstehen und zum Glück uns alle gegenseitig helfen." (weiblich, 14, Syrien)

„Wir verstehen uns alle. Und meine Mitschüler versuchen, mir immer viel zu helfen." (weiblich, 17, Syrien)

„Wir verstehen uns gut. Es gibt keinen Streit.“ (weiblich, 17, Irak)

„Es sind alle nett zu mir. Und wenn ich etwas nicht verstehe, dann helfen sie mir.“ (männlich, 15, Irak)

„Es ist alles sehr schön. Wir sind wie eine Familie.“ (männlich, 16, Irak)

54 der 80 Befragten besuchen eine reguläre Schule (Sekundarschule, Hauptschule, Realschule, Gesamtschule, Gymnasium). Sieben sind auf einer Berufsschule und 18 in einer Vorbereitungsklasse. Die meisten Befragten, die in Deutschland aufgewachsene Mitschülerinnen und Mitschüler haben, beschreiben das Verhältnis zu ihnen als positiv.

„Ich habe das Gefühl, dass die deutschen Mitschüler sich für mich freuen, wenn ich Fortschritte mache." (weiblich, 14, Syrien)

„Ich habe viel Kontakt zu deutschen Mitschülern und bin oft mit denen zusammen. Das trägt dazu bei, meine Leistung zu steigern und gut zu lernen.“ (männlich, 16, Afghanistan)

„Ehrlich gesagt konnte ich durch meine Freunde am besten Deutsch lernen. Die Lehrer konnten mir das nicht so gut beibringen. “ (männlich, 15, Irak)

„Meine deutschen Mitschüler sind meine Freunde, und sie helfen mir in der Schule. “(männlich, 17, Irak)

„Ich muss sagen, dass ich nicht mit komplett allen deutschen Mitschülern befreundet bin, aber den meisten. Wir verstehen uns sehr gut, und ich kann sie immer alles fragen." (weiblich, 14, Syrien) 


\section{Junge Geflüchtete sind teilweise rassistischen Anfeindungen durch Mitschülerinnen und Mitschüler ausgesetzt.}

Einige der Befragten berichten jedoch auch von negativen Erfahrungen, die sie mit deutschen Mitschülerinnen und Mitschülern gemacht haben. Hier reicht das Spektrum von Hänseleien bis hin zu explizit diskriminierendem Verhalten bezüglich der Herkunft oder Religion. Dieses Verhalten der deutschen Mitschülerinnen und Mitschüler wird von den Jugendlichen oft als sehr verletzend erlebt.

„Einen Tag fühlt man sich gut. An zehn Tagen fühlt man sich schlecht. Ich kann mich nicht mit meinen Klassenkameraden gleichstellen, die hier geboren sind. Sie sind eingebildet und rassistisch. Das Thema tut mir weh, wenn wir darüber reden." (männlich, 16, Irak)

„,Meine Mitschüler haben mich immer so angeguckt, als ob ich ein schlimmer Mensch wäre. Das hat mir schon sehr wehgetan." (weiblich, 17, Syrien)

„Die Deutschen dort reichen einem nicht einmal die Hand. Ich hatte nur den Amerikaner oder andere ausländischen Freunde." (männlich, 17, Afghanistan)

„Die Schüler mag ich auch nicht. Die haben alle Angst vor mir, weil ich aus einer Gangster-Gegend komme.“ (männlich, 15, Syrien)

„Sie gucken böse. Manche sagen auch, dass ich ein Flüchtling bin und wieder zurück in meine Heimat soll. Ich ignoriere sie meistens, vor allem die Mädchen. Mit den Jungs streite ich mich manchmal." (weiblich, 17, Syrien)

„Wenn ich mich mit jemandem anfreunden möchte, dann wollen manche sich nicht anfreunden. Sie sehen in uns immer nur die Ausländer, obwohl wir im gleichen Alter sind. [...] Die Rassisten müssten gehen, aus meiner Klasse, aus meiner Schule.“ (männlich, 15, Irak)

\subsubsection{Zufriedenheit mit der Schulleitung und der Ausstattung der Schule}

Die meisten Befragten sind mit der schulischen Ausstattung bzw. Infrastruktur vor Ort zufrieden. Nur die Schülerinnen und Schüler in Vorbereitungsklassen äußern diesbezüglich vereinzelt Kritik.

Befragt nach der Zufriedenheit mit verschiedenen Aspekten rund um die Schule zeigt sich, dass die Ausstattung der Schulen sowie die Schulleitungen am wenigsten kritisiert werden. Die Ausstattung wird als modern und umfangreich beschrieben - insbesondere im Vergleich mit den Schulen der Herkunftsländer. 
„Meine Schule ist modern wie eine Universität.“ (männlich, 16, Syrien)

„Die anderen Schüler sagen, dass unsere Schule richtig hässlich ist. Aber ich denke, im Vergleich zu der Schule in Afghanistan ist sie viel besser." (weiblich, 17, Afghanistan)

„Es gibt hier Sachen, die wir im Irak nicht hatten.“ (männlich, 16, Irak)

Einige Schülerinnen und Schüler, die derzeit eine Vorbereitungsklasse besuchen, kritisieren hingegen, dass die Schulen nur unzureichend ausgestattet sind bzw. man in „Ersatzklassenzimmern“" unterrichtet wird.

„Die Schule ist schon sehr alt. Sie ist vor langer Zeit gebaut worden.“ (männlich, 15, Syrien)

„Im Irak war es moderner als in meiner jetzigen Schule. Immerhin gibt es hier eine Heizung. Aber im Sommer ist es zu heiß.“ (männlich, 17, Irak)

„Wir haben keinen Klassenraum. Mal sind wir in diesem Raum und mal in jenem. Die anderen Schüler haben alle einen festen Klassenraum. Wir hingegen haben manchmal auch in der Küche Unterricht, wenn es sein muss." (männlich, 17, Afghanistan)

„Wir haben z. B. keine Bücher und kein extra Material.“ (weiblich, 17, Irak)

\section{Die jungen Geflüchteten, die schon Kontakt zu Schulleitungen hatten, sind mit diesen zufrieden.}

Nur wenige der Befragten berichten davon, schon einmal direkten Kontakt mit der Schulleitung gehabt zu haben. Diejenigen, bei denen dies der Fall ist, zeigen sich in der Regel zufrieden. Sie beschreiben die schulischen Führungskräfte als kompetent und sympathisch. Nur wenige berichten von gegenteiligen Erfahrungen.

„Mit dem Schulleiter habe ich erst einmal gesprochen. Ich habe ihn gefragt, ob er mich in eine Klasse mit deutschen Kindern steckt, da meine Noten ziemlich gut waren. Er meinte jedoch, dass ich vorerst die Klasse nicht wechseln darf. Das war also bisher unser einziger Kontakt." (männlich, 17, Afghanistan)

„Die Schulleitung ist nett, aber sehr langweilig.“ (weiblich, 17, Irak)

„Unser Kunstlehrer ist ja der Schulleiter, ein sehr wissender Mann und ein guter Mensch." (weiblich, 15, Afghanistan) 


\subsubsection{Zufriedenheit mit außerschulischen Angeboten und künstlerischen Fächern}

\section{Außerschulische Angebote und kreative Fächer kommen bei jungen Geflüchteten gut an. Allerdings haben nicht alle Zugang zu diesen Angeboten.}

Unabhängig von der besuchten Schulform berichten die meisten Jugendlichen davon, dass sie an außerschulischen Aktivitäten teilnehmen. Dass sie aus einem vielfältigen Angebot wählen können, das sich mit den eigenen Interessen deckt, ist für viele neu und aufregend. Besonders beliebt sind Angebote in den Bereichen Sport, Musik und Tanz, bildende Kunst, Kochen, Fremdsprachen und Technologie. Auch engagieren sich einige der Befragten im Rahmen politischer bzw. sozialer Angebote (z. B. ,Schule ohne Rassismus“). Vereinzelt werden Angebote besonders dann positiv bewertet, wenn sie interkulturellen Dialog ermöglichen.

„Man kann richtig frei wählen, was man tun will oder was man für Fächer haben will. Das ist alles gut. Ich bin damit ganz zufrieden." (weiblich, 17, Afghanistan)

„Wir können nach dem Unterricht verschiedene AGs besuchen. Da kann jeder machen, worauf er Lust hat. Da kann man malen, kochen, neue Sprachen lernen und viele andere Dinge machen. Ich habe mich für Malen entschieden." (weiblich, 17, Irak)

„Wir haben sehr viele Möglichkeiten. Wir können fotografieren, tanzen, Musik machen." (weiblich, 17, Irak)

„Es gibt AGs. Ich bin in der Sport-AG. Es gibt noch Spanisch und Französisch, aber das ist schwer." (männlich, 16, Syrien)

„Die Angebote gefallen mir. Ich bin in der Sport- und Spiele-AG.“ (männlich, 15, Irak)

„Wir machen manchmal Ausflüge. Das ist auch gut, weil wir dann etwas mehr von Deutschland sehen." (männlich, 17, Syrien)

„Wir haben eine AG. Sie beschäftigt sich mit ,Schule ohne Rassismus - Schule mit Courage'. Es geht um Kinder- und Frauenrechte und um Gleichberechtigung zwischen Männern und Frauen. Und zurzeit machen wir einen Frauentag." (weiblich, 16, Syrien)

Unabhängig von der besuchten Schulform kritisieren einige der Befragten aber auch, dass sie keinen oder nur einen eingeschränkten Zugang zu außerschulischen Angeboten oder kreativen Fächern haben. Mit Blick auf Exkursionen wird auch beklagt, dass Auslandsreisen aufgrund von Visa-Problemen nicht möglich sind. 
„Es gibt keine Angebote. Ich wünsche mir eine Pfadfinder-AG.“ (männlich, 17, Syrien)

„Ich kann nicht so gut Kunst, aber wenn es angeboten werden würde, würde ich das gerne belegen, weil ich wirklich schwach darin bin." (weiblich, 17, Afghanistan)

„Ich hätte gerne mehr Musikunterricht.“ (weiblich, 14, Irak)

„Solche Fächer haben wir nicht. Malen würde ich gerne.“ (männlich, 17, Eritrea)

„Nächstes Jahr wollen wir eine Klassenfahrt nach Irland machen. Aber ich weiß nicht, ob ich in Irland einreisen darf." (männlich, 15, Syrien)

\section{Besonders diejenigen schulischen und außerschulischen Angebote sind beliebt, die den Jugendlichen die Möglichkeit zu kreativer Selbst- verwirklichung und künstlerischem Kompetenzerwerb geben.}

Neben Sport mögen die Jugendlichen besonders Aktivitäten aus dem künstlerischen bzw. kreativen Bereich (bildende Kunst, Musik, Theater). Mit Blick auf musikalische Bildungsangebote wird vor allem die Möglichkeit zum Erlernen eines Instruments positiv hervorgehoben. Diesbezüglich würden sich die Jugendlichen jedoch wünschen, dass die eigenen musikalischen Interessen stärker berücksichtigt würden (z. B. arabische Musik oder Deutsch-Rap).

Auch Angebote aus dem Bereich der bildenden Künste sind den Jugendlichen sehr wichtig. Zum einen, weil sie dort technische Fertigkeiten ausbilden können, zum anderen weil ihnen Kunst bei der Bewältigung von Problemen hilft bzw. ein Ventil darstellt, um Emotionen zum Ausdruck zu bringen.

Aus ähnlichen Gründen wenden sich Jugendliche auch den Theaterangeboten zu. Hier geht es ihnen darum, sich durch künstlerischen Ausdruck selbst zu verwirklichen, Rollen bzw. Identitäten auszuprobieren und nicht zuletzt Aufmerksamkeit zu erhalten.

„Ich bin zufrieden, wir haben sowohl eine Kunstklasse als auch Musik.“ (weiblich, 14, Afghanistan)

„Ich liebe es. Mir gefällt Kunst sehr.“ (männlich, 15, Irak)

„Ich kann dort Musik machen, z. B. mit dem Klavier oder anderen Instrumenten. Also ich mag es, das zu lernen." (männlich, 15, Syrien)

„Ich mag Kunst. Ich bin in der Kunst-AG. Das ist eine kleine Leidenschaft von mir. Wenn ich nichts zu tun habe, zeichne ich gerne. Zurzeit versuche ich, Menschen realer zu zeichnen. Ich übe aber noch daran." (männlich, 15, Syrien)

„Der Schulleiter unterrichtet Kunst bei uns. Der Unterricht ist sehr gut. Es malt nicht nur einfach ein Bild, er zeigt uns viele Techniken. In Afghanistan hatte ich 
keinen Kunstunterricht. Ich hatte ja nicht mal normalen Unterricht. Aber Kunst ist ganz neu für mich." (weiblich, 15, Afghanistan)

„Mit der Theater-AG bin ich sehr zufrieden, da es wirklich sehr spitze ist und sie sehr viel mit den Jugendlichen unternehmen." (männlich, 17, Afghanistan)

„Ich habe schon mal bei einem Theater in der Schule mitgemacht. Ich war gut. Ich musste weinen, und das war sehr glaubhaft. Man hat nicht erkannt, dass ich nur schauspiele. Ich würde auch gern eine Ausbildung zum Schauspieler machen." (männlich, 17, Irak)

\section{Nur wenige der Befragten interessieren sich nicht für außerschulische Angebote oder finden, dass sie vom Kernunterricht ablenken.}

Während die meisten Jugendlichen außerschulische Angebote gerne annehmen, interessieren sich einige nicht dafür. Gründe hierfür sind Desinteresse an den Angeboten oder ein Schul- bzw. Bildungsverständnis, demzufolge in der Schule keine kreaktiven Fächer unterrichtet werden sollten. Auch führen einige die Sprachbarriere als Zugangsbeschränkung zu außerschulischen Angeboten an. Einige betonen, dass sie sich außerschulische Angebote erst dann widmen möchten, wenn sie Sprachdefizite aufgearbeitet haben.

„Wir haben keine Kunst und keine Musik. Eine Schule ist nicht für so etwas da." (männlich, 16, Syrien)

„Ich mag so etwas nicht machen. Ich habe keine Zeit für so etwas. Sobald die Schule fertig ist, komme ich nach Hause, dann esse ich, und dann gehe ich schlafen." (weiblich, 17, Afghanistan)

„Da gibt es nichts. Du bist ja da, um die Sprache zu lernen.“ (männlich, 17, Eritrea)

\subsubsection{Zufriedenheit mit der Möglichkeit zur Ausübung religiöser Praxis in der Schule}

\section{Einige der Jugendlichen beklagen, dass sie ihre Religion in der Schule nicht angemessen ausüben können.}

Ungefähr die Hälfte der Befragten nutzte das Interview, um sich zur Möglichkeit des Ausübens ihrer Religion in der Schule zu äußern. Darunter finden sich vor allem junge Muslime, denen tägliche Gebete wichtig sind. In dieser Gruppe sind die meisten (unabhängig von der besuchten Schulform) tendenziell eher unzufrieden mit den Möglichkeiten religiöser Praxis in der Schule. Ein zentraler 
Grund für die geäußerte Unzufriedenheit ist dabei das Mittagsgebet. Hier fehlen aus Sicht der Jugendlichen sowohl das entsprechende Zeitfenster als auch die entsprechenden Räumlichkeiten. In den Fällen, in denen Zeitfenster und Räumlichkeiten von den Schulen angeboten werden, zeigen sich die Jugendlichen zufrieden.

„Die sollen mir Zeit geben, damit ich beten kann.“ (männlich, 17, Afghanistan)

„Ich bete in der Schule nicht. Wo soll ich denn beten? “ (männlich, 17, Syrien)

„Ich wünsche mir, dass ich beten kann und es einen sauberen Raum gibt, in dem man sich waschen kann. Aber das gibt es nicht." (weiblich, 17, Afghanistan)

„Ein Gebetsraum wäre schon gut. Ich schaffe es im Winter manchmal nicht, das Mittagsgebet zu verrichten. Aber die Lehrer haben mir schon angeboten, dass ich auch im Lehrerraum beten könnte." (weiblich, 16, Syrien)

„Es wäre schön, so etwas zu haben, aber in Deutschland würde man kein Verständnis dafür haben. Es wäre z. B. schön, einen Raum zu haben, wo nur die Mädchen in der Pause beten könnten, damit sie das Gebet nicht verpassen." (weiblich, 17, Syrien)

Es gibt aber auch viele religiöse Jugendliche, die mit der Schule zufrieden sind, obwohl die Ausübung der religiösen Praxis dort nicht uneingeschränkt möglich ist. Diese Jugendlichen sind der Meinung, dass das Gebet zu Hause ausreichend sei oder dass sie trotz eigener Religiosität keinen Wert auf religiöse Praxis in der Schule legen, weil sie das schulische und private Leben bewusst voneinander trennen möchten.

„Ich glaube, da gibt es keine Möglichkeit. Aber ich habe ja Zeit, wenn ich von der Schule komme. Dann kann ich das auch zu Hause machen." (weiblich, 17, Afghanistan)

„Man kann auch zu Hause beten.“ (weiblich, 17, Syrien)

„Das Thema spielt in der Schule für mich keine Rolle.“ (männlich, 17, Afghanistan)

„Im eigenen Land hatten wir das auch nicht, also warum hier? “ (weiblich, 14, Irak)

\section{Angst vor Stigmatisierung hindert einige muslimische Jugendliche an der Ausübung religiöser Praxis in der Schule.}

Die Angst vor religiöser Diskriminierung hindert manche der befragten muslimischen Jugendlichen daran, in der Schule zu beten. Einige fühlen sich als Außenseiter ohne Anrecht auf das Privileg des freien Ausübens von Religion. 
„Ich kann in der Schule nicht beten. Ich sage nichts, weil das hier sowieso nicht realisiert werden kann. Wir sind in einem christlichen Land.“ (männlich, 17, Irak)

Einige berichten, dass es anti-islamische Ressentiments an der Schule gibt, denen sie aus dem Weg gehen möchten. Diese Jugendlichen berichten davon, dass sie von ihren Mitschülerinnen und Mitschülern wegen ihrer Religionszugehörigkeit nicht gemocht werden. In einigen Fällen begründet sich diese Wahrnehmung auch über unmittelbare Diskriminierungserfahrungen.

„Einige Mitschüler haben meine Religion beleidigt und mich beleidigt. Ich ignoriere die einfach." (männlich, 15, Syrien)

„In Afghanistan habe ich einen Hijab getragen, aber hier nicht. Ich habe ihn hier in Deutschland am Anfang auch getragen, aber dann haben sich andere Mädchen darüber lustig gemacht, und ich mochte das nicht. Dann habe ich entschieden, ihn nicht mehr zu tragen." (weiblich, 15, Afghanistan)

„Ich kann in der Schule wegen des Ansehens bei den anderen Mitschülern nicht beten. Ich möchte die Religion nicht zur Schule mitnehmen. Ich hätte Angst, dass die anderen dann etwas Schlechtes denken. Sie würden dann sagen ,Bombe bauen oder so." (männlich, 15, Irak)

„Ich habe nicht das Gefühl, in der Schule meinen Glauben leben zu können. Es gibt z. B. auch kein Fach wie Religion oder so. Und sonst habe ich nicht das Gefühl, dass ich neben den anderen meine Religion stark leben könnte, ich glaube, sie würden das nicht gutheißen. “ (weiblich, 17, Syrien)

„Ich praktiziere meinen Glauben nicht in der Schule. Ich nähere mich solchen Problemen nicht. Ich mag darüber überhaupt nicht reden." (männlich, 17, Irak)

„Auf der einen Seite würde ich sehr gerne in der Schule beten. Dann müsste ich auch zu Hause nicht nachbeten. Aber auf der anderen Seite würden sich die Mitschüler über mich lustig machen, dann könnte ich mich nicht konzentrieren." (weiblich, 14, Irak)

„Ich wünsche mir keinen Gebetsraum, sonst wird man von den anderen noch mehr gehasst." (männlich, 16, Irak)

\section{Junge Muslime, die Kopftücher tragen, haben unterschiedliche Haltungen zum Tragen eines Kopftuchs in der Schule.}

Alle befragten Muslime befürchten, aufgrund eines Kopftuchs stigmatisiert zu werden - auch in der Schule. Manche verzichten deshalb auf das Kopftuch. Unter denjenigen, die trotz der wahrgenommenen Vorbehalte ein Kopftuch in der Schule tragen, reagieren einige sehr selbstbewusst und lassen sich nicht davon abhalten - 
auch wenn sie bereits persönlich in der Schule mit religiösen Ressentiments konfrontiert wurden. Diese Befragten tragen das Kopftuch aus fester Überzeugung, auch wenn dies zu Diskriminierungserfahrung führen kann.

„Ich bin die einzige Muslimin, bzw. es sind vielleicht andere auch muslimisch, aber ich bin die einzige, die ein Kopftuch trägt. Ich habe das Gefühl, dass meine Mitschüler manchmal denken, dass ich mich eher wie sie anziehen sollte. Aber ich bin überzeugt von meinem Kopftuch, und ich denke, dass jeder so etwas für sich selbst entscheiden muss. Ich denke das, weil sie manchmal so etwas sagen wie: ,Wieso ziehst du nicht das und das an?'Ich wünschte, wir hätten eine Schuluniform, dann wäre es besser." (weiblich, 17, Syrien)

„Manchmal habe ich das Gefühl, dass meine Mitschüler das Kopftuch als etwas Schlechtes sehen. Aber ich muss sagen, dass ich in der Schule bis jetzt ohne Probleme damit herumlaufen konnte. Ich glaube, ich kann meine Religion dort sehr gut ausleben." (weiblich, 14, Syrien)

„Ich habe ja selbst vor, wenn ich 18 Jahre alt bin, ein Kopftuch zu tragen. Ich habe das Gefühl, dass das in der Schule nicht so gut angesehen wird. Ich mache mir manchmal darüber Gedanken, wie das wohl sein wird. Manchmal sagen die anderen Mitschüler schon heute, dass sie es komisch oder fremd finden, zumindest zeigen sie das so, z. B. durch Blicke.“ (weiblich, 14, Syrien)

„Ich denke, dass meine Lehrkräfte und die Mitschüler meine Religion nicht so gerne sehen. Es gibt z. B. eine syrische Freundin, die ein Kopftuch trägt. Irgendwie redet niemand richtig mit ihr. Und wenn ich mit ihr zusammen bin, dann sehen sie das auch nicht gerne. Sie selbst sagt auch, dass sie es so empfindet." (weiblich, 15, Syrien)

Dem gegenüber gibt es einige, die trotz innerer Überzeugung aus Angst vor Benachteiligungen in der Schule kein Kopftuch tragen. Dabei wird nicht nur die Angst vor negativen Reaktionen der Mitschülerinnen und Mitschüler angesprochen, sondern auch die Befürchtung geäußert, dass Lehrende Ressentiments hegen könnten. Es gibt aber auch junge Muslime, die froh sind, dass es ihnen in Deutschland freigestellt ist, ob sie ein Kopftuch tragen möchten oder nicht. Darüber hinaus geben einige der Befragten an, dass sie das Kopftuch nur aufgrund von sozialem Druck ihres familiären Umfelds tragen.

„Theoretisch könnte ich, wenn ich es wollte, auch ein Kopftuch anziehen, also ich bin in diesem Sinne frei und kann das entscheiden. Ich möchte aber keins tragen, weil ich so, wie ich jetzt bin, zufrieden bin." (weiblich, 17, Syrien) 
„Meine Freundinnen sagen auch oft zu mir: ,Zieh doch ein Kopftuch an', ich sage aber, das ist nichts Schönes, und ein Mädchen mit Kopftuch kann nicht alles tun, was es mag. Manchmal trage ich auch ein Kreuz als Kette. Manchmal bin ich eine Christin, manchmal eine Muslimin und manchmal eine Jüdin.“(weiblich, 17, Irak)

\subsubsection{Zufriedenheit mit schulischer Unterstützung und Anerkennung}

\section{Die Jugendlichen erhalten von verschiedenen Seiten gezielte schulische Unterstützung - vor allem von Lehrerinnen und Lehrern.}

Ein weiterer Aspekt, der zur Zufriedenheit mit dem Schulalltag beiträgt, ist die gezielte Unterstützung der Jugendlichen in der Schule. Einige Lehrkräfte bemühen sich laut Aussagen der Befragten in besonderem Maße um die schulische Teilhabe und das generelle Wohlbefinden von jungen Geflüchteten und engagieren sich sogar in ihrer Freizeit. Dafür sprechen die Jugendlichen Wertschätzung und Dankbarkeit aus.

„Die Lehrer helfen viel und wiederholen sehr viel. Die haben sogar vorgeschlagen, dass sie uns extra am Wochenende bei uns zu Hause unterstützen möchten. Das bedeutet mir sehr viel." (männlich, 17, Afghanistan)

„Meine Lehrer waren nicht nur Lehrer für mich, sie kümmern sich um mich wie meine Mutter." (weiblich, 15, Irak)

„Mein Mathelehrer kommt alle zwei Wochen und nimmt sich extra Zeit für uns.“ (männlich, 17, Afghanistan)

„Die Lehrer helfen uns viel, und unsere Klassenlehrerin hilft uns nicht nur bei Schulsachen und Fragen, sie hilft auch besonders viel den Mädchen. Sie bietet uns ihre Hilfe an; wenn ein Mädchen z. B. etwas bedrückt oder nervt, dann erzählt sie das der Lehrerin. Sie hat sehr viel Mitgefühl für uns." (weiblich, 17, Syrien)

„Wir haben Nachhilfelehrer in der Schule. Die helfen mir sehr. Ohne deren Unterstützung wäre ich bei Weitem noch nicht so weit, wie ich es jetzt bin." (männlich, 17, Eritrea)

\section{Die schulische Unterstützung wird jedoch nicht immer als ausreichend empfunden.}

Obwohl sich der Großteil der Befragten zufrieden zeigt mit der Unterstützung durch die Lehrkräfte, so würden sich einige mehr Engagement von ihnen wünschen - insbesondere hinsichtlich des Erlernens der deutschen Sprache. Die einen 
sprechen den Lehrenden zwar guten Willen zu, finden aber, dass dies nicht reicht. Teilweise wird fehlende Unterstützung darin begründet, dass die Lehrerinnen und Lehrer zeitlich so eingebunden sind, dass mehr Engagement kaum möglich ist. Andere hingegen beschweren sich darüber, dass manche Lehrkräfte sich keine Mühe geben, sie stärker zu fördern. Viele der Schülerinnen und Schüler an Gymnasien zeigen sich mit der Unterstützung durch Lehrkräfte deutlich zufriedener als Schülerinnen und Schüler anderer Schularten.

„Die Lehrer helfen mir sehr. Beispielsweise wenn ich etwas nicht verstehe. Aber ich würde mir noch mehr Hilfe wünschen." (weiblich, 14, Syrien)

„Wir sind viele Schüler, man kann nicht immer nachfragen.“ (weiblich, 17, Irak)

„Ich bin in der Hausaufgaben-AG. Da wird mir bei den Hausaufgaben geholfen. Ich wünsche mir, dass die Hausaufgaben-AG öfters stattfindet. Jetzt findet sie immer nur zweimal in der Woche statt. Ich bräuchte noch eine Nachhilfe." (männlich, 17, Irak)

„Die Lehrerin hilft mir gar nicht. Sie redet ununterbrochen weiter, und dann macht sie mich an, warum ich zu Hause nicht lese. Ich lese, so wie ich kann, also langsam. Das ist ihr aber nicht genug. " (weiblich, 17, Irak)

„Wenn jemand Deutscher ist und Deutsch seine Muttersprache ist, dann weiß er alles. Um die sollten sich die Lehrer nicht so stark kümmern. Sie sollten lieber denen helfen, die das noch nicht können. Sie sollten ihre Zeit mehr denen widmen, nicht den Deutschen." (weiblich, 17, Afghanistan)

\section{Neben den Lehrkräften nennen die Jugendlichen vor allem Mitschüler- innen und Mitschüler, Freundinnen und Freunde sowie nicht schulische Einrichtungen als wichtige Anlaufstellen zur Unterstützung.}

Die jungen Geflüchteten berichten, dass sie auch von Schulkameradinnen und -kameraden viel Unterstützung erfahren. Das hat einen positiven Effekt nicht nur auf die Zufriedenheit mit Schule im Speziellen, sondern auch auf die Lebenszufriedenheit außerhalb von Schule im Allgemeinen.

\footnotetext{
„Wir helfen einander. Jeder hilft jedem.“ (männlich, 17, Irak)

„Im Unterricht frage ich die Lehrerin, und in den Pausen frage ich meine Freundin. Sie hilft mir. Wir gehen manchmal in die Bibliothek und lernen dort gemeinsam." (männlich, 17, Irak)

„Meine deutschen Mitschüler sind meine Freunde, und sie helfen mir in der Schule.“ (männlich, 17, Irak)
} 
„Die deutschen Mitschüler sind alle nett zu mir, und wenn ich etwas nicht verstehe, dann helfen sie mir.“ (männlich, 15, Irak)

Zudem erhalten manche Jugendliche auch Unterstützung von nicht schulischen Institutionen, z. B. von Hausaufgabenbetreuerinnen und -betreuern aus ihren Einrichtungen, von Non-Profit-Organisationen aus dem Bildungssektor, von Mitgliedern aus Pflegefamilien und vom Jugendamt.

„Ich besuche außerhalb der Schule noch spezielle Deutschkurse, weil ich die Sprache verbessern möchte." (männlich, 17, Afghanistan)

„In der Gelben Villa werden wir auf den mittleren Schulabschluss vorbereitet, die helfen uns dort. Sie haben uns immer Fragen gegeben, und es wurde erklärt, was drankommen könnte. Ich bin dort hingegangen. Am Ende haben sie mir gesagt, dass ich für meinen Mathekurs nichts Neues lernen kann, weil ich das alles schon in der Schule hatte. Deswegen habe ich mich am Ende abgemeldet." (weiblich, 17, Syrien)

„In der Schule haben wir einmal in der Woche Studenten, die uns Nachhilfe geben und helfen. Für andere Nachhilfe muss ich beim Jugendamt einen Antrag stellen.“ (männlich, 16, Syrien)

\section{Die Zufriedenheit mit der Schule steigt, wenn die Jugendlichen nicht nur fachliche Unterstützung, sondern auch persönliche Anerkennung von Lehrkräften und Mitschülerinnen und Mitschülern erfahren.}

Die befragten Jugendlichen geben zu erkennen, dass ihre Zufriedenheit mit der Schule nicht nur damit zusammenhängt, wie sehr sie von Lehrenden und von Mitschülerinnen und Mitschülern fachlich unterstützt werden, sondern auch damit, ob ihnen für ihre Bemühungen in der Schule Anerkennung entgegengebracht wird. Wichtig sind nicht nur fachliche Erfolge wie gute Noten, sondern auch die Anerkennung informeller Kompetenzen oder künstlerischer Begabungen sowie persönliche Wertschätzung.

„Ich habe das Gefühl, wirklich Anerkennung zu bekommen, weil die Lehrer mich loben, nachdem wir etwas besprochen haben." (weiblich, 15, Syrien)

„Die Lehrer sagen mir oft, dass ich die Tests und die Hausaufgaben gut erledigt habe. Das freut mich dann. Die deutschen Mitschüler sagen mir auch, wenn ich etwas gut gemacht habe." (weiblich, 14, Syrien)

„Ich habe das Gefühl, dass die deutschen Mitschüler sich für mich freuen, wenn ich Fortschritte mache." (weiblich, 14, Syrien) 
„Als ich in der 8. Klasse war, war meine Lehrerin sehr zufrieden mit mir. Wir hatten z. B. darstellendes Spiel, und meine Lehrerin war so zufrieden gewesen, dass sie mir einen Brief schrieb. Sie schrieb, dass sie sehr zufrieden mit mir war. Ich hatte zwei Rollen in dem Theaterstück, eine Rolle war die Hauptrolle. Sie hatte sich gefreut." (weiblich, 15, Irak)

„Die Mitschüler bauen mich auch immer auf und sagen: „Du schaffst es.“ (weiblich, 14, Irak)

Von den befragten Jugendlichen, die keine Anerkennung aus ihrem schulischen Umfeld erhalten, sind die meisten auch insgesamt unzufriedener mit ihrem Schulalltag. Einige der Befragten beklagen, dass ihre schulischen Leistungen nicht hinreichend von den Lehrkräften gewürdigt werden. Andere kritisieren auch, dass es ihren Lehrkräften generell an Empathie für die Situation von jungen Geflüchteten fehle. Solche Erfahrungen führen bei einigen auch dazu, dass sie nicht nur unzufrieden mit der Schule sind, sondern an sich selbst zu zweifeln beginnen.

„Nur eine Lehrerin zeigt mir Anerkennung. Sie weiß, dass ich etwas kann. So sollten alle Lehrer sein." (männlich, 17, Syrien)

„Ich habe das Gefühl, dass die Lehrer kein Verständnis dafür haben, dass ich noch nicht so lange hier bin." (weiblich, 17, Syrien)

„Ich wünsche mir, dass die Lehrer die Geflüchteten normal behandeln und verstehen. Viele Geflüchtete schämen sich, ihre Probleme zu benennen. Wir sind neu in Deutschland und kennen das System nicht." (männlich, 17, Afghanistan)

Open Access Dieses Kapitel wird unter der Creative Commons Namensnennung 4.0 International Lizenz (http://creativecommons.org/licenses/by/4.0/deed.de) veröffentlicht, welche die Nutzung, Vervielfältigung, Bearbeitung, Verbreitung und Wiedergabe in jeglichem Medium und Format erlaubt, sofern Sie den/die ursprünglichen Autor(en) und die Quelle ordnungsgemäß nennen, einen Link zur Creative Commons Lizenz beifügen und angeben, ob Änderungen vorgenommen wurden.

Die in diesem Kapitel enthaltenen Bilder und sonstiges Drittmaterial unterliegen ebenfalls der genannten Creative Commons Lizenz, sofern sich aus der Abbildungslegende nichts anderes ergibt. Sofern das betreffende Material nicht unter der genannten Creative Commons Lizenz steht und die betreffende Handlung nicht nach gesetzlichen Vorschriften erlaubt ist, ist für die oben aufgeführten Weiterverwendungen des Materials die Einwilligung des jeweiligen Rechteinhabers einzuholen.

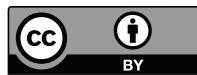

